\title{
Stereological study of the neuronal number and volume of 38 brain subdivisions of subjects diagnosed with autism reveals significant alterations restricted to the striatum, amygdala and cerebellum
}

Jerzy Wegiel ${ }^{1 *}$, Michael Flory², Izabela Kuchna ${ }^{1}$, Krzysztof Nowicki ${ }^{1}$, Shuang Yong Ma ${ }^{1}$, Humi Imaki ${ }^{1}$, Jarek Wegiel ${ }^{1}$, Ira L Cohen ${ }^{3}$, Eric London ${ }^{3}$, Thomas Wisniewski ${ }^{4}$ and William Ted Brown ${ }^{5}$

\begin{abstract}
Introduction: A total of 38 brain cytoarchitectonic subdivisions, representing subcortical and cortical structures, cerebellum, and brainstem, were examined in 4- to 60-year-old subjects diagnosed with autism and control subjects (a) to detect a global pattern of developmental abnormalities and (b) to establish whether the function of developmentally modified structures matches the behavioral alterations that are diagnostic for autism. The volume of cytoarchitectonic subdivisions, neuronal numerical density, and total number of neurons per region of interest were determined in 14 subjects with autism and 14 age-matched controls by using unbiased stereological methods.

Results: The study revealed that significant differences between the group of subjects with autism and control groups are limited to a few brain regions, including the cerebellum and some striatum and amygdala subdivisions. In the group of individuals with autism, the total number and numerical density of Purkinje cells in the cerebellum were reduced by $25 \%$ and $24 \%$, respectively. In the amygdala, significant reduction of neuronal density was limited to the lateral nucleus (by 12\%). Another sign of the topographic selectivity of developmental alterations in the brain of individuals with autism was an increase in the volumes of the caudate nucleus and nucleus accumbens by $22 \%$ and $34 \%$, respectively, and the reduced numerical density of neurons in the nucleus accumbens and putamen by $15 \%$ and $13 \%$, respectively.
\end{abstract}

Conclusions: The observed pattern of developmental alterations in the cerebellum, amygdala and striatum is consistent with the results of magnetic resonance imaging studies and their clinical correlations, and of some morphometric studies that indicate that detected abnormalities may contribute to the social and communication deficits, and repetitive and stereotypical behaviors observed in individuals with autism.

Keywords: Autism, Brain, Volume, Number of neurons, Cerebellum, Striatum, Amygdala

\footnotetext{
* Correspondence: jerzy.wegiel@opwdd.ny.gov

'Department of Developmental Neurobiology, NYS Institute for Basic

Research in Developmental Disabilities, 1050 Forest Hill Road, Staten Island,

NY 10314, USA

Full list of author information is available at the end of the article
} 


\section{Introduction}

Autism is a lifelong disorder characterized by disrupted development of social and communication skills and restricted, repetitive, and stereotypical patterns of behavior, interests, and activities. In nearly $50 \%$ of individuals later diagnosed with autism, functional alterations are noted at between 14 and 24 months, and alterations are observed in all three diagnostic functional domains at 24 months of age $[1,2]$.

In the past three decades, numerous studies have been conducted on the trajectory of brain overgrowth, differences between the sizes of individual brain structures and regions, and the abnormal number and size of neurons in the brain in autism spectrum disorder (ASD). A large cluster of studies has focused on distortion of the trajectory of brain growth, which may involve modifications of the brain and of brain structure volumes as well as of the number of neurons. A rapid increase in head circumference at 1-2 years of age [3-7] followed by a slower rate of brain growth between 2 and 4 years of age [8-11] reportedly results in only a $2 \%$ larger brain size in adult patients with autism [12] or a smaller brain size [13] in comparison to control subjects. However, recent analysis by Raznahan et al. [14] revealed that the vast majority (83\%) of head circumference studies in ASD used head circumference norms as comparison data. Reassessment of evidence of early brain overgrowth revealed that studies using head circumference norms are significantly more likely to identify head circumference abnormalities in ASD than are comparisons between head circumference data of children with ASD and locally recruited control subjects [14]. The authors of this analysis suggest that reports of early brain overgrowth in children with ASD reflect replicable Centers for Disease Control and Prevention norm biases rather than a disease-related phenomenon. However, there is no doubt that in several genetic syndromes characterized by autistic-like behavior, the brain is enlarged [15], or affected individuals are microcephalic $[16,17]$.

Individual brain structures have distinct developmental profiles from the trajectory of brain development [18-20]. Growth abnormalities of various brain regions involved in cognitive, social, and emotional functions and language development are considered to be a reflection of their contribution to the clinical autism phenotype [9-11,21]. Some postmortem studies suggest that volumetric changes are associated with an increase or decrease in the number of neurons. Courchesne et al. [22] revealed 67\% more neurons in the prefrontal cortex in 2- to 16-year-old individuals with autism and linked these differences to prenatal disturbances of mechanisms that govern proliferation, cell cycle regulation, and apoptosis. Santos et al. [23] demonstrated insignificantly more von Economo neurons in the frontoinsular cortex in 4- to 11-year-old children diagnosed with autism than in controls $(p=0.054)$, but the contribution of this small population of neurons to the volume of this cortical region is marginal. However, the majority of reports show that the numbers of many neuronal populations in the brain structures of individuals with autism are unmodified [23-28] or regionally decreased [29-34].

This project was designed to partially reduce the limitations of research outcome due to the small size of the cohort examined with (a) different methods of tissue preservation and evaluation and (b) concentration of the study on a few brain regions. Four parameters-brain weight, the volume of brain structures' cytoarchitectonic subdivisions, the total number of neurons, and the numerical density of neurons per region of interest-were selected to detect developmental and age-associated alterations in the brains of 14 individuals diagnosed with autism and 14 control subjects. The aim of the study of 14 brain structures and their 24 subdivisions (layers, sectors, nuclei) including subcortical and cortical structures, cerebellum, and brainstem was to identify a global pattern of alterations and to establish whether the function of altered structures matches the behavioral alterations that are diagnostic for autism.

\section{Materials and methods}

Originally, 39 brains were assigned to this study of developmental abnormalities in autism, including 21 brains of subjects diagnosed with autism and 18 control brains. Application of clinical inclusion criteria and neuropathological exclusion criteria reduced the size of this cohort to 28 subjects, comprising 14 subjects with autism and 14 age-matched control individuals. Two cases did not meet the Autism Diagnostic Interview-Revised (ADI-R) [1] criteria for diagnosis of autism. One affected subject and four control subjects were excluded because of severe brain autolysis, and the brains of three subjects with autism were excluded because of hypoxic encephalopathy, and another one because of multiple microinfarcts [35].

The clinical diagnosis of autism was confirmed by a postmortem application of the ADI-R. Results of the ADI-R and the clinical characteristics of this cohort have been summarized by Wegiel et al. [35]. Eight subjects with autism $(57 \%)$ were affected by mild to severe intellectual deficits, which were detected using the Wechsler Intelligence Scale for Children III and the WoodcockJohnson Tests of Achievement-Revised. Seven of the 14 subjects with autism were diagnosed with seizures (50\%), and in five cases (36\%), death was seizure-related.

Neuropathological evaluation revealed various types of developmental abnormalities in 13/14 brains of individuals diagnosed with autism (93\%), which were summarized in our previous report [36], including (a) defects of proliferation with subependymal nodular dysplasia, (b) defects of 
migration resulting in subcortical and periventricular heterotopias, and (c) dysplastic changes in the neocortex, archicortex, dentate gyrus, Ammons horn, and cerebellum.

The study has been approved by the institutional review board (Application \# 463) of the New York State Institute for Basic Research in Developmental Disabilities.

\section{Tissue processing, embedding, sectioning, and staining}

Tissue samples, demographics of individuals with autism and control subjects, brain weight, and changes during processing were characterized in our previous report [35]. In short, the postmortem interval (PMI), corresponding to the period between death and autopsy, ranged from 6 to 28 hours in the control group, and from 3 to 50 hours in the affected group, but the difference in PMI between the two groups was not significant. The average weight of the brains in the cohort with autism (1,453 g) was not significantly different from that in the control group (1,372 g). The brain hemisphere was fixed with $10 \%$ buffered formalin for an average of 408 days in the control group and 905 days in the affected group. Brain dehydration in a series of ascending concentrations of ethyl alcohol for 36 and 38 days in the control and affected groups, respectively, resulted in reduction of brain hemisphere weight by $47 \%$ on average in the group of subjects diagnosed with autism and by $45 \%$ in the control group. Brain hemispheres were embedded in $8 \%$ celloidin [37]. Serial $200-\mu \mathrm{m}$-thick sections stained with cresyl violet and mounted with Acrytol were used for morphometric studies.

\section{Delineation of regions of interest}

The anatomical boundaries of the examined brain structures and their cytoarchitectonic subdivisions were described in detail in our previous report [35]. Delineation of structures requiring micrographs is illustrated with Figures 1 and 2, which show partitioning of the striatum (caudate nucleus, putamen, nucleus accumbens and globus pallidus); the amygdala (lateral, basal, accessory basal and central nuclei); layers of the entorhinal cortex; and sectors in the Ammons horn.

The rostral striatum is divided into the caudate nucleus and the putamen by the internal capsule. The border between the nucleus accumbens, the caudate nucleus and the putamen was arbitrarily defined by a line perpendicular to the midline of the internal capsule at its ventral end [38]. The number of striatal small neurons was estimated but a few dispersed large neurons [39] were not included in this study. The external medullary lamina marks the border between the putamen and the globus pallidus. The medial medullary lamina divides the globus pallidus into the external and internal pallidum [40]. The number of neurons was determined in both parts of the pallidum. The boundaries of the lateral, basal, accessory basal and central nuclei were delinated using cytoarchitectonic criteria described in detail by Schumann and Amaral [31,41]. The entorhinal cortex (EC, Brodmann area 28) occupies the gyrus ambiens and the anterior portion of the hippocampal gyrus. The anterior border of the EC starts a few millimeters rostrally to the amygdala complex. The EC ends rostrally to the lateral geniculate body. The medial portion of the EC borders with the preamygdaloid cortex and caudally with the subicular complex. The lateral portion of the EC borders with Brodmann area 35, which lacks a distinct layer IV [42]. The transentorhinal zone [43] was not included in this study. Neurons were measured within four layers of the EC. Layer II consists of islands of large modified pyramidal and stellate neurons separated by an acellular gap from layer III. A broad layer III is built up of mediumsized pyramidal neurons separated from layer $\mathrm{V}$ by the lamina dissecans, labeled as layer IV. Layer V consists of the large pyramidal neurons, whereas Layer VI is built up of the smallest neurons with a decreasing gradient of neuronal density in the deep portion of this layer [42].

In Ammon's horn the number of neurons was estimated in the pyramidal layer in sectors CA1-4. The CA1 sector pyramidal neuronal layer extends from the subiculum to the CA2 sector as a thick band of medium size pyramidal neurons. Two features distinguish the CA2 sector: a compact arrangement of large pyramidal neurons and the lowest thickness of this layer. The size of neurons in the CA3 and 4 is similar, but parallel arrangement of neurons in the CA3 sector distinguishes CA3 from randomly dispersed neurons in the hilus, identified also as CA4 sector $[42,44]$. The mapping of sectors on serial sections was based on the Amaral and Insausti [42] classification, but the CA4 sector has been delinated as a separate subdivision.

The neurons were distinguished from glial cells by using histological features revealed by cresyl violet staining, including neuron size, shape, and spatial orientation typical for specific layers, sectors, and brain nuclei, as well as the pattern of staining of nuclear chromatin, the distinct nucleolus in the majority of examined neuronal populations, and cytoplasm morphology. Small and round nuclei with uniform, intense staining of nuclear chromatin distinguished oligodendrocytes from astrocytes with large, round nuclei with a small amount of dispersed chromatin and an undetectable nucleolus.

\section{Stereological analysis}

Volume evaluation and counting of neurons were performed using a workstation consisting of an Axiophot II (Carl Zeiss, Goettingen, Germany) light microscope with Plan-NEOFLUAR objectives-1.25 $\times$ (numerical aperture, N. A., 0.035$), 2.5 \times$ (N.A. 0.075$), 5 \times$ (N.A. 0.15$), 20 \times$ (N.A. 0.5$)$, 

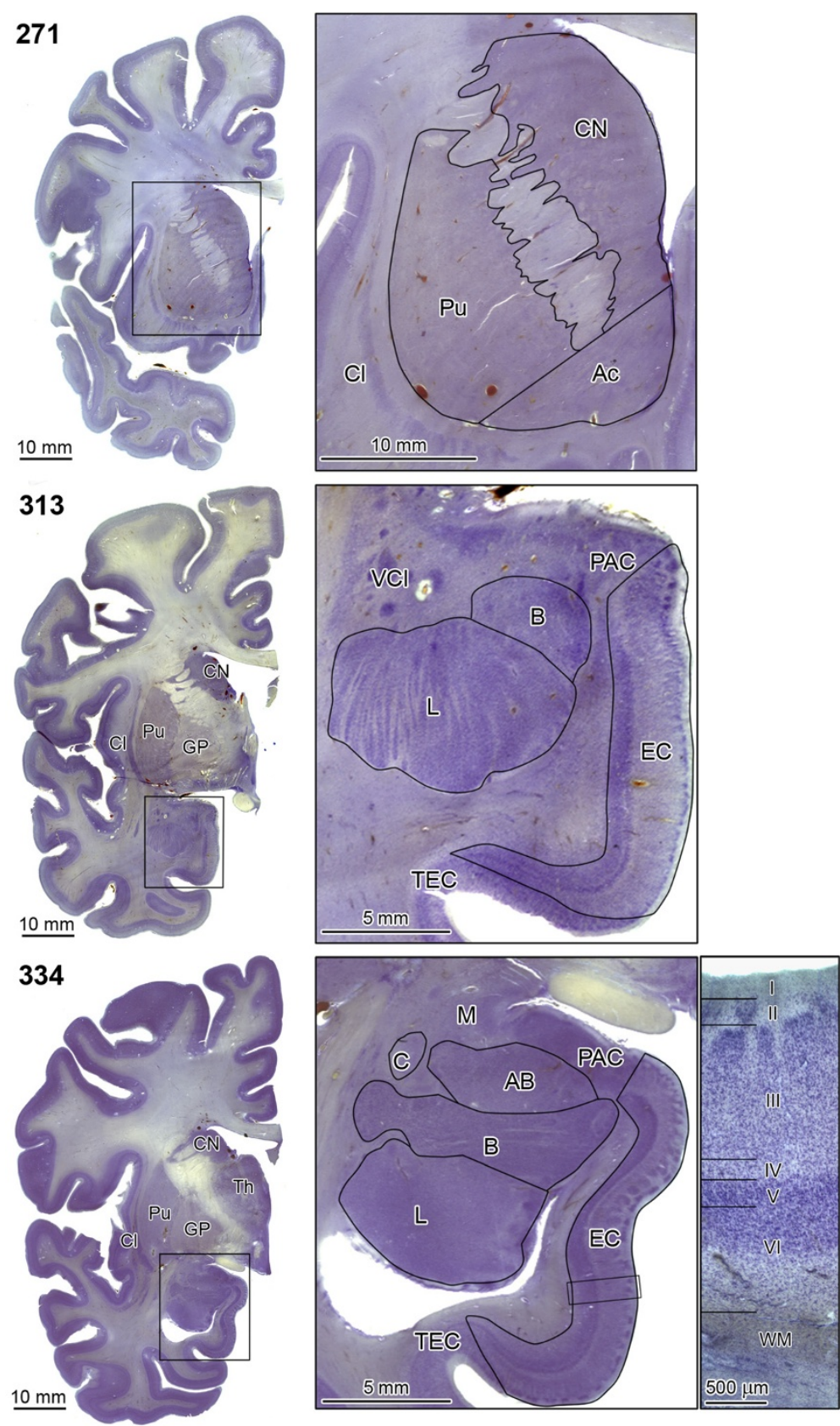

A

\section{B}

C

Figure 1 Delineation of the striatum subdivisions, the amygdala nuclei and anterior portion of the entorhinal cortex. Panel A shows three serial coronal sections (271, 313, and 334) stained with cresyl violet. Rectangles mark inserts that are shown enlarged in panel B. Section 271 shows delineation of the caudate nucleus (CN), putamen (Pu) and nucleus accumbens (Ac). Enlargements of sections 313 and 334 demonstrate the borders of the lateral (L), basal (B), accessory basal (AB), and central (C) nuclei within the amygdaloid complex. The adjacent median (M) nucleus, preamygdaloid cortex (PAC), and ventral claustrum (VCl) are marked. The borders of the enorhinal cortex (EC) are delinated including the borderline with the transentorhinal cortex (TEC) and PAC. Higher magnification (Panel C) shows EC layers typical for the mid-level of the rostrocaudal EC extension including layer I (molecular layer); islands of stellate neurons in layer II; a broad layer III; and acellular layer IV. On this level large darkly stained neurons form narrow layer $(V)$, whereas the broad layer $V l$ is built up of the smallest neurons, with decreasing gradient of neuronal density in the deeper part of this layer and a diffuse border with white matter (WM). Other examined structures: globus pallidus (GP), claustrum (Cl), and thalamus (Th). Calibration bar length: $10 \mathrm{~mm}, 5 \mathrm{~mm}$, and $500 \mu \mathrm{m}$. 

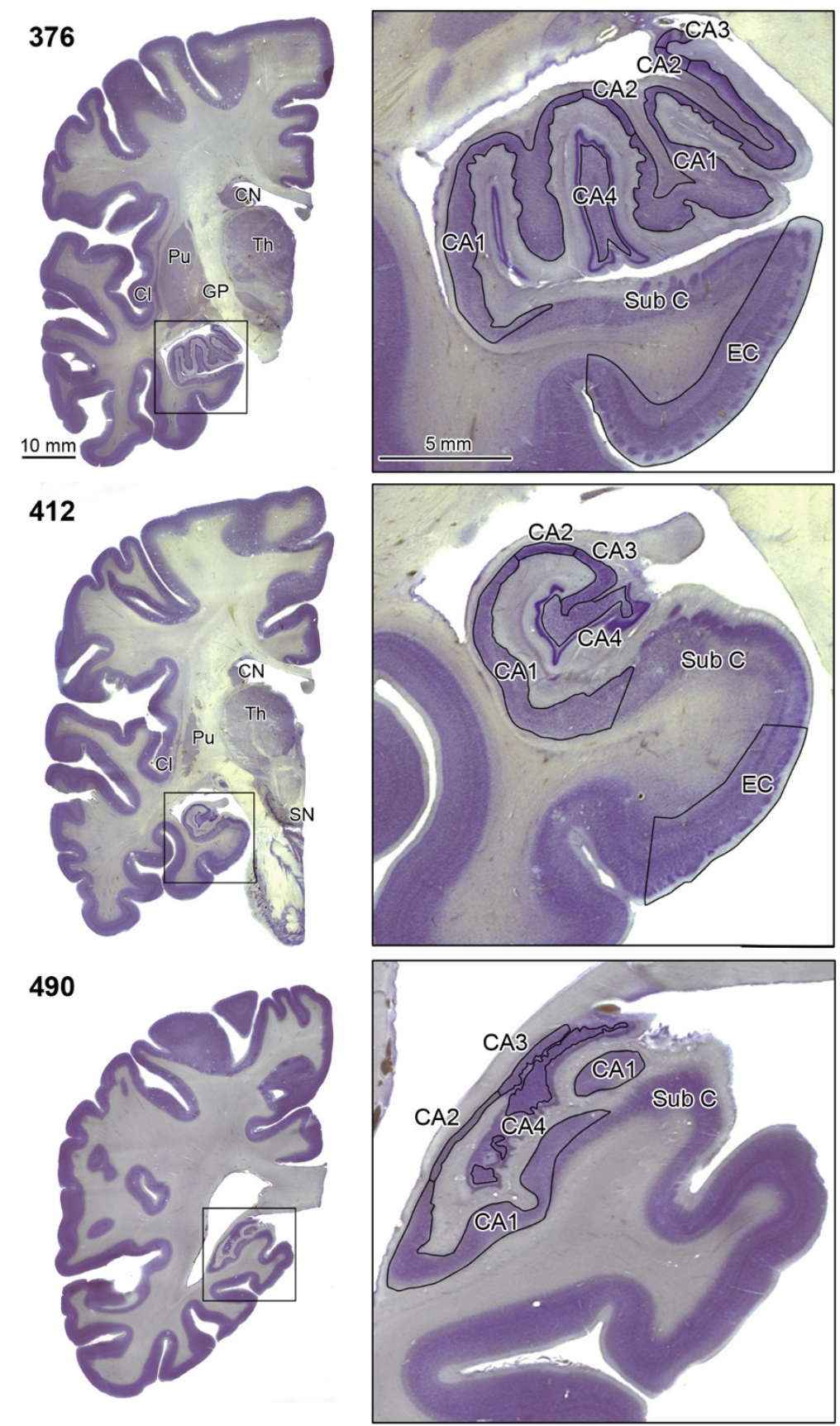

A

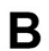

Figure 2 Delination of the Ammons horn sectors and the posterior portion of the entorhinal cortex. Panel A shows CV-stained hemispheric sections on the level of the hippocampal head (s. 376), body (s. 412) and tail (s. 490). The rectangle in panel $\mathbf{A}$ marks an area that was enlarged 5-fold and is shown in panel $\mathbf{B}$. Stereologically examined structures are labeled as: sectors CA1, 2, 3, 4; EC, entorhinal cortex; CN, caudate nucleus; Pu, putamen; GP, globus pallidus; Cl, claustrum; Th, thalamus; and SN, substantia nigra. The subicular complex is labeled as Sub C. Calibration bar length: $10 \mathrm{~mm}$ and $5 \mathrm{~mm}$.

and $40 \times($ N.A. 0.75$)$; a specimen stage with a three-axis, computer-controlled stepping motor system (Ludl Electronics; Hawthorne, NY, USA); a CCD color video camera (CX9000, MicroBrightfield Bioscience, Inc., Williston, VT,
USA); and stereology software (Stereo Investigator, MicroBrightfield Bioscience).

The parameters and procedures that were applied to estimate the volume of brain regions and the number of 
neurons are summarized in Table 1. Brain structures and their subdivisions were delineated at a low magnification of $1.25 \times(47 \times$ final mag.), $2.5 \times(95 x)$, or $5 \times(190 x)$ to determine the volume of the region of interest. The number of neurons was estimated by using a 40x lens (final magnification, 1,450x), and the number of Purkinje cells, by using a 20x lens (final magnification, 720x). The numerical density of Purkinje cells $\left(\mathrm{n} / \mathrm{mm}^{3}\right)$ was estimated in the cerebellar cortex, including molecular and granule cell layers. An optical fractionator systemic random sampling scheme was applied (Stereo Investigator, MicroBrightfield). Twelve equidistant serial sections were used for neuronal counts in the anatomical subdivisions of the amygdala; 10 in the substantia nigra; 14 in cornu Ammonis sectors CA1-CA4; 13 in the claustrum; 16 in the magnocellular basal complex; 6 in the thalamus, entorhinal cortex, globus pallidus, and nucleus accumbens; 9 in the caudate nucleus and putamen; 8 in the cerebellum and in the inferior olive; and 11 in the dentate nucleus. The bias related to sectioning defects was reduced by application of 5 - $\mu \mathrm{m}$-wide top and bottom guard zones. The results of examination of the cytoarchitectonic subdivisions are presented as the mean number of neurons per $\mathrm{mm}^{3}$ (neuronal density) and the total number of neurons per region of interest. The sizes of the grid and of the virtual counting space were adjusted to the size and shape of the examined regions. The number of virtual counting spaces ranged from 62 per subdivision per case in a very small subdivision such as the fifth layer in the entorhinal cortex (coefficient of error; CE, 0.003) to 1953 in the globus pallidus with a low neuronal numerical density (CE, 0.04).

The mean volumes, number of neurons, and neuronal density of structures in autistic and control brains were compared in analyses of covariance (ANCOVAs) and repeated measures analysis of variance in which brain weight and, for neuronal counts and density, log age, post-mortem interval, and days of fixation were entered

Table 1 Parameters and procedures applied to estimate the volume of brain subdivisions and number of neurons

\begin{tabular}{|c|c|c|c|c|c|c|c|c|}
\hline $\begin{array}{l}\text { Structures and } \\
\text { their subdivisions }\end{array}$ & $\begin{array}{l}\text { Number of } \\
\text { sections examined } \\
\text { (per case) }\end{array}$ & $\begin{array}{l}\text { Obj. } \\
\text { (Vol.) }\end{array}$ & $\begin{array}{l}\text { Obj. } \\
\text { (Numb.) }\end{array}$ & $\begin{array}{l}\text { Grid size } \\
(\mu \mathrm{m}) \text { for } \\
\text { fractionator }\end{array}$ & $\begin{array}{l}\text { Test area } \\
\text { frame } \times \text { height } \\
(\mu \mathrm{m})\end{array}$ & $\begin{array}{l}\text { Number of } \\
\text { counting spaces } \\
\text { (per case) }\end{array}$ & $\begin{array}{l}\text { Number of } \\
\text { neurons counted } \\
\text { (per case) }\end{array}$ & $\mathrm{CE}^{*}$ \\
\hline Amygdala (four nuclei) & 12 & $1.25 x$ & $40 x$ & $1000 \times 1000$ & $80 \times 80 \times 10$ & 356 & 454 & 0.01 \\
\hline Thalamus & 6 & $1.25 x$ & $40 x$ & $1000 \times 1000$ & $80 \times 80 \times 10$ & 188 & 313 & 0.01 \\
\hline \multicolumn{9}{|l|}{ Entorhinal c. } \\
\hline LII & 6 & $2.5 x$ & $40 x$ & $400 \times 400$ & $60 \times 60 \times 30$ & 113 & 164 & 0.003 \\
\hline LIII & 6 & $2.5 x$ & $40 x$ & $800 \times 800$ & $60 \times 60 \times 30$ & 118 & 277 & \\
\hline LV & 6 & $2.5 x$ & $40 x$ & $600 \times 600$ & $60 \times 60 \times 30$ & 62 & 161 & \\
\hline LVI & 6 & $2.5 x$ & $40 x$ & $800 \times 800$ & $60 \times 60 \times 30$ & 68 & 184 & \\
\hline CA1 & 14 & $2.5 x$ & $40 x$ & $1000 \times 1000$ & $60 \times 60 \times 30$ & 207 & 543 & 0.003 \\
\hline CA2 & 14 & $2.5 x$ & $40 x$ & $400 \times 400$ & $60 \times 60 \times 30$ & 121 & 337 & \\
\hline CA3 & 14 & $2.5 x$ & $40 x$ & $400 \times 400$ & $60 \times 60 \times 30$ & 144 & 330 & \\
\hline CA4 & 14 & $2.5 x$ & $40 x$ & $600 \times 600$ & $100 \times 100 \times 30$ & 130 & 429 & \\
\hline Caudate nucleus & 9 & $2.5 x$ & $40 x$ & $1400 \times 1400$ & $60 \times 60 \times 30$ & 270 & 751 & 0.04 \\
\hline Putamen & 9 & $2.5 x$ & $40 x$ & $1400 \times 1400$ & $60 \times 60 \times 30$ & 309 & 844 & \\
\hline Globus pallidus & 6 & $2.5 x$ & $40 x$ & $300 \times 300$ & $80 \times 80 \times 30$ & 1953 & 505 & \\
\hline Nucleus accumbens & 6 & $2.5 x$ & $40 x$ & $700 \times 700$ & $60 \times 60 \times 30$ & 202 & 749 & \\
\hline Magnocellular LGB & 4 & $5 x$ & $40 x$ & $500 \times 500$ & $100 \times 100 \times 30$ & 96 & 230 & 0.002 \\
\hline Parvocellular LGB & 4 & $5 x$ & $40 x$ & $500 \times 500$ & $100 \times 100 \times 30$ & 134 & 1,418 & 0.002 \\
\hline Claustrum & 13 & $1.25 x$ & $40 x$ & $250 \times 250$ & $60 \times 60 \times 10$ & 274 & 318 & 0.01 \\
\hline Substantia nigra & 10 & $2.5 x$ & $40 x$ & $500 \times 500$ & $80 \times 80 \times 30$ & 366 & 493 & 0.002 \\
\hline $\begin{array}{l}\text { Magnocellular basal complex } \\
\text { (Ch1-Ch4) }\end{array}$ & 16 & $2.5 x$ & $40 x$ & $500 \times 500$ & $80 \times 80 \times 30$ & 323 & 507 & 0.005 \\
\hline Dentate nucleus & 11 & $2.5 x$ & $40 x$ & $1000 \times 1000$ & $180 \times 180 \times 30$ & 335 & 792 & 0.002 \\
\hline Inferior olive & 8 & $2.5 x$ & $40 x$ & $1000 \times 1000$ & $180 \times 180 \times 30$ & 213 & 364 & 0.002 \\
\hline Cerebellum & 8 & $1.25 x$ & $20 x$ & $1800 \times 1800$ & $180 \times 180 \times 30$ & 1419 & 773 & 0.05 \\
\hline
\end{tabular}

Number of sections examined $=$ mean number of equidistant sections examined per structure/case.

Obj. (Vol.) = Objective lens $(1.25 x, 2.5 x$, or $5 x)$ used to provide final magnification for planimetry and volumetry.

Obj. (Numb.) = Objective lens $(40 x$ or $20 x)$ used for fractionator to estimate neuronal density and total number of neurons.

${ }^{*} \mathrm{CE}=$ the average predicted Coefficient of Error of the neuronal counts (Scheaffer). 
as covariates. Pearson correlations were computed for age and the total number and density of neurons in the autistic and control cohort.

\section{Results}

\section{Repeated measures analysis of variance}

To test the hypotheses that structures differ in the degree to which autism affects, first, the number of neurons in the structure and, second, the volume of the structure, we conducted repeated measures analyses of variance with structure and autistic status as factors, with the potential confounders of brain weight, post-mortem interval, days of fixation, and log age entered as covariates. The significant interaction of structure with autistic status in each case indicates that autism's effect upon the number of neurons $(\mathrm{F}[\mathrm{df}=13]=2.138, \mathrm{p}<.018)$ and upon structural volume $(\mathrm{F}[\mathrm{df}=13]=10.278, \mathrm{p}<.001)$ differs among the structures examined.

\section{Volume of brain subdivisions}

In the control group, the volume of 14 brain structures and their 24 subdivisions ranged from the largest structures, such as the thalamus, putamen, and caudate nucleus $\left(2,999 \mathrm{~mm}^{3}, 2,365 \mathrm{~mm}^{3}\right.$, and $1,727 \mathrm{~mm}^{3}$, respectively) to the smallest inferior olive $\left(59 \mathrm{~mm}^{3}\right)$ (Figure 3). Table 2 summarizes the results of estimation of the volume of brain regions and their cytoarchitectonic subdivisions as the absolute volume calculated using mounted section thickness (StereoInvestigator, Microbrightfield). To compare the results of volume estimates with other reports, the volume was corrected for $47 \%$ tissue shrinkage during dehydration for the autism group and $45 \%$ shrinkage for the control group. A significant difference between the volumes of the examined structures in the affected and control cases was detected only in the caudate nucleus and nucleus accumbens. In the group with autism, caudate nucleus volume was larger by $22 \%$ $\left(2,107 \mathrm{~mm}^{3}\right.$ in the autism cohort, and $1,727 \mathrm{~mm}^{3}$ in the control cohort; $p<0.036)$. The nucleus accumbens was larger by $34 \%\left(244 \mathrm{~mm}^{3}\right.$ in the autism cohort, and $182 \mathrm{~mm}^{3}$ in the control cohort; $p<0.050$ ). However, analysis of alterations in 4- to 8-year-old children did not reveal a significant difference between the affected and control groups. The finding of a significantly larger caudate nucleus and nucleus accumbens only in 9- to 60-yearold individuals with autism suggests that the difference may be a result of changes during adolescence/adulthood.

The mean volume of the examined cerebellar hemisphere was almost identical in the affected and control groups: $31,779 \mathrm{~mm}^{3}$ and $31,133 \mathrm{~mm}^{3}$, respectively. The mean volume of the molecular and granule cell layers $\left(12,623 \mathrm{~mm}^{3}\right.$ and $12,092 \mathrm{~mm}^{3}$, respectively), and the percentage of the cerebellar cortex occupied by these two layers (51\% and $49 \%$, respectively) in the group with autism did not reveal a significant difference in comparison to the control group $\left(12,885 \mathrm{~mm}^{3}\right.$ and $11,926 \mathrm{~mm}^{3}$, respectively; with the volume ratio $52 \%$ and $48 \%$, respectively). The mean volume of white matter was almost the same in the affected and control cohorts $\left(6,700 \mathrm{~mm}^{3}\right.$ and $6,005 \mathrm{~mm}^{3}$, respectively), as was the percentage of the cerebellar volume occupied by white matter $(21 \%$ and $19 \%$, respectively). Also, the volume of cerebellar nuclei (364 $\mathrm{mm}^{3}$ and $317 \mathrm{~mm}^{3}$, respectively), including the largest dentate nucleus $\left(244 \mathrm{~mm}^{3}\right.$ and $232 \mathrm{~mm}^{3}$, respectively), did not reveal a significant difference between individuals with autism and control subjects.

\section{Number of neurons}

Application of the fractionator method to determine the total number of neurons in 15 brain structures and their 16 cytoarchitectonic subdivisions in control subjects (Table 3) revealed 49 million to 65 million neurons in the three largest structures, including the thalamus, caudate nucleus, and putamen, and 7 million to 15 million in medium-size structures such as the nucleus accumbens, amygdala, entorhinal cortex, claustrum, and Ammons horn. In the smallest examined brain structures, the number of neurons ranged from 0.7 million in the substantia nigra to 1.4 million in the lateral geniculate body. Examination of 31 brain regions and cytoarchitectonic subdivisions revealed a significantly lower total number of neurons only in the second layer of the entorhinal cortex $(813,252$ in subjects with autism and 1,023,270 in control subjects; $p<0.013$ not corrected for log of age, brain weight, postmortem interval, and days of fixation). In two affected cases, neuronal deficit in the entorhinal cortex was detected without the support of morphometric methods, as the paucity of focal stellate neurons in disorganized islands that were smaller than normal. However, a reduction of the mean total number of neurons to 788,879 and the shift of significance to $p<0.007$ after removal of these two cases from the analysis indicates that these focal developmental defects contribute less to the decrease of the mean number of stellate neurons than do diffuse deficits not detectable without morphometric support.

The numerical density of neurons was brain regionspecific and varied in the control group from $2,339 / \mathrm{mm}^{3}$ in the globus pallidus to $40,031 / \mathrm{mm}^{3}$ in the nucleus accumbens. In the group with autism, a significantly lower numerical density of neurons was detected in three brain regions: the lateral nucleus in the amygdala $(24,390 /$ $\mathrm{mm}^{3}$ in the affected group and $27,446 / \mathrm{mm}^{3}$ in the control group; $p<0.017)$, putamen $\left(23,749 / \mathrm{mm}^{3}\right.$ in the affected group and $27,531 \mathrm{~mm}^{3}$ in the control group; $p<0.041$ ), and nucleus accumbens $\left(33,107 / \mathrm{mm}^{3}\right.$ in the affected group and $40,031 / \mathrm{mm}^{3}$ in the control group; $p<0.018$ ). Box plots demonstrate that in the majority of subjects with autism the numerical density of Purkinje cells, neurons in the 

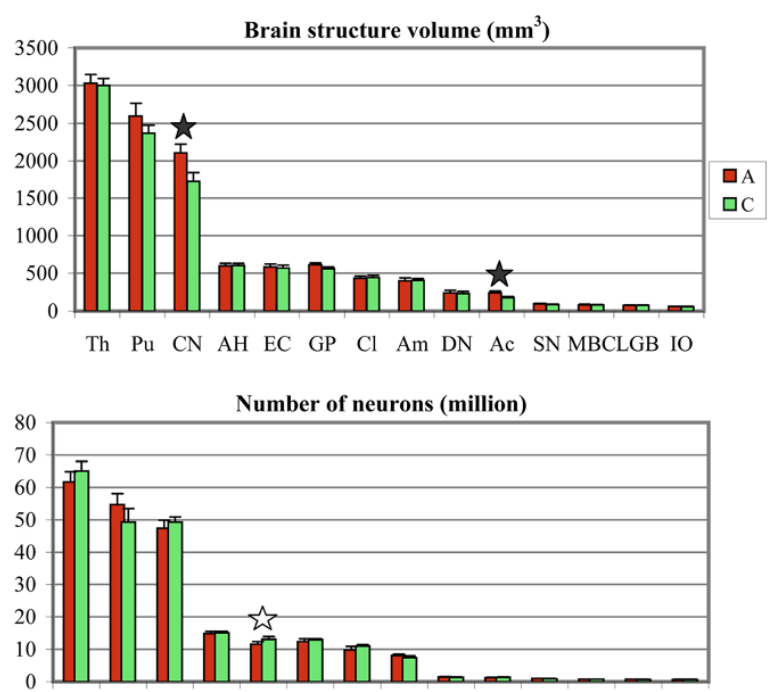

$\mathrm{Pu} \quad \mathrm{CN}$ Th $\mathrm{AH}$ EC $\mathrm{Cl}$ Am Ac LGB GP DN MBC IO SN

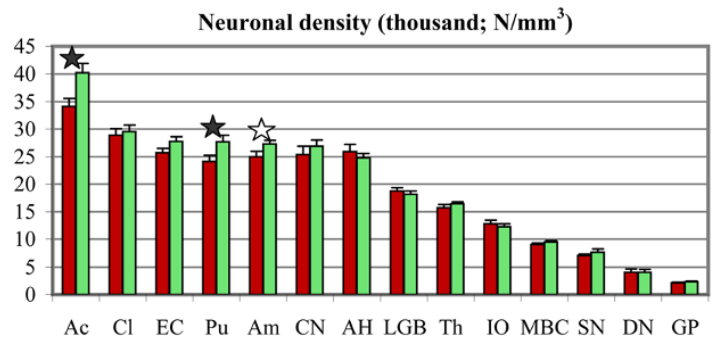

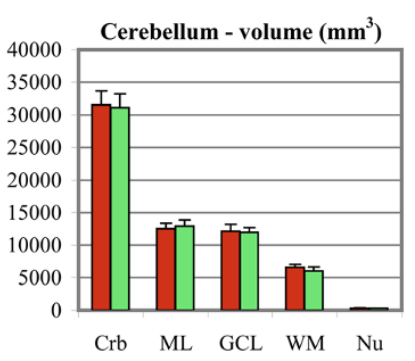

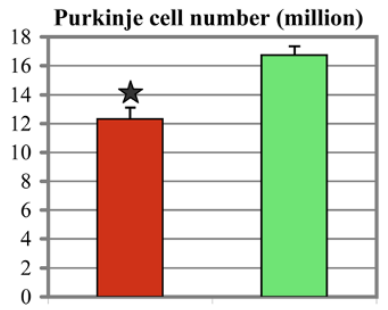

A

$\mathrm{C}$

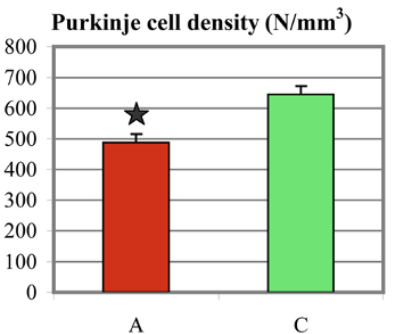

Figure 3 Brain structure volume, total number of neurons and neuronal density. Range of the volume of examined regions from the largest (thalamus, putamen, and caudate) to the smallest (inferior olive). The volume of all four striatum subdivisions, including putamen, caudate nucleus, globus pallidus, and nucleus accumbens, is greater in subjects with autism, but the difference in this volume between affected and control subjects is significant only in the caudate and nucleus accumbens (black stars). The total number of neurons was found to be significantly less only in the second layer of the entorhinal cortex (white star) when covariates were not entered in the analysis. Although the total number of neurons does not reveal significant differences, the numerical density is significantly reduced in the nucleus accumbens and putamen of subjects with autism. The significantly lower numerical density of neurons is observed in the lateral nucleus of the amygdala (white star), but not in other amygdala nuclei. Cerebellar volume and the volume of the molecular and granule cell layers, cerebellar white matter, and cerebellar nuclei do not reveal differences between affected and control subjects; however, the total number of Purkinje cells was $25 \%$ less ( $p<0.03$ ) in the group with autism (12.1 million) than in the control group (16.0 million). The numerical density of Purkinje cells was also significantly less ( $p<0.004)$ in the affected group than in the control group $\left(488 / \mathrm{mm}^{3}\right.$ and $645 / \mathrm{mm}^{3}$, respectively). Th, Thalamus; Pu, putamen; CN, caudate nucleus; AH, Ammons horn; EC, entorhinal cortex; GP, globus pallidus, Cl, claustrum; Am, amygdala; DN, dentate nucleus; Ac, nucleus accumbens; SN, substantia nigra; MBC, magnocellular basal complex; LGB, lateral geniculate body; IO, inferior olive; Crb, cerebellum; ML, molecular layer; GCL, granule cell layer; WM, white matter; Nu, cerebellar nuclei.

lateral nucleus in the amygdala, nucleus accumbens and in the putamen is less than the median numerical density in the control group (Figure 4).

The volume of cerebellum and cerebellar subdivisions as well as the number of neurons was estimated after exclusion of records for brain samples of two subjects with autism: one with focal defects of cresyl violet staining related to poor fixation, and the second because of focal dysplasia. A 60-year-old subject with autism and clinically diagnosed disturbed movement coordination and postmortem-detected severe hypoplasia of cerebellar lobes I-IV [36] was excluded from statistical analysis to eliminate the impact of one case of focal developmental defect on estimates of developmental alterations in an examined group of subjects with autism. In this cerebellum, the numerical density of Purkinje cells was 2.3 times less $\left(274 / \mathrm{mm}^{3}\right)$ in the hypoplastic area than in the control cerebellar cortex. The total number of Purkinje cells was $42 \%$ less in this case ( 7.1 million) than the mean total number in the examined hemisphere of other subjects with autism and $65 \%$ less than in the control group.

The average total number of Purkinje cells within the examined cerebellar hemispheres was significantly less $(p<0.0001)$ in the group with autism (12.1 million) than in the control cohort (16. million) (25\% deficit). The minimal number of Purkinje cells in the examined hemisphere in the control group was 11.4 million, but in five 
Table 2 Mean volume ( \pm SE) of 14 brain structures and 24 cytoarchitectonic subdivisions in one brain hemisphere of autistic and control subjects*

\begin{tabular}{|c|c|c|c|c|c|}
\hline \multirow[t]{2}{*}{$\begin{array}{l}\text { Brain structure or cytoarchitectonic } \\
\text { subdivision }\end{array}$} & \multicolumn{3}{|c|}{$\begin{array}{l}\text { Volume }\left(\mathrm{mm}^{3}\right) \text { (Absolute volume calculated using } \\
\text { mounted section thickness) }\end{array}$} & \multicolumn{2}{|c|}{$\begin{array}{l}\text { Volume }\left(\mathrm{mm}^{3}\right) \text { corrected } \\
\text { for shrinkage }\end{array}$} \\
\hline & Autism & Control & $p<$ & Autism & Control \\
\hline Thalamus & $3,030 \pm 116$ & $2,999 \pm 92$ & ns & 5,717 & 5,453 \\
\hline Putamen & $2,597 \pm 165$ & $2,365 \pm 111$ & ns & 4,900 & 4,300 \\
\hline Caudate nucleus & $2,107 \pm 114$ & $1,727 \pm 114$ & 0.036 & 3,975 & 3,140 \\
\hline Cornu Ammonis (CA) & $598 \pm 33$ & $602 \pm 30$ & ns & 1,128 & 1,096 \\
\hline - CA1 & $439 \pm 22$ & $432 \pm 23$ & ns & 828 & 785 \\
\hline - CA2 & $32 \pm 3$ & $36 \pm 2$ & ns & 60 & 65 \\
\hline - CA3 & $44 \pm 3$ & $45 \pm 4$ & ns & 83 & 82 \\
\hline - CA4 & $84 \pm 7$ & $89 \pm 6$ & ns & 158 & 162 \\
\hline Entorhinal cortex (EC) I-VI & $589 \pm 39$ & $557 \pm 36$ & ns & 1,111 & 1,012 \\
\hline$-\mathrm{ECI}$ & $71 \pm 4$ & $63 \pm 4$ & ns & 134 & 115 \\
\hline - EC II (Islands) & $38 \pm 3$ & $42 \pm 4$ & ns & 72 & 76 \\
\hline$-E C I I I$ & $254 \pm 17$ & $244 \pm 16$ & ns & 479 & 444 \\
\hline$-E C I V$ & $23 \pm 3$ & $17 \pm 5$ & ns & 43 & 31 \\
\hline$-E C V$ & $60 \pm 4$ & $62 \pm 5$ & ns & 113 & 113 \\
\hline$-E C V I$ & $143 \pm 10$ & $129 \pm 9$ & ns & 270 & 234 \\
\hline Globus pallidus & $611 \pm 36$ & $561 \pm 25$ & ns & 1,153 & 1,020 \\
\hline - External globus pallidus & $412 \pm 28$ & $364 \pm 29$ & ns & 777 & 662 \\
\hline - Internal globus pallidus & $199 \pm 10$ & $197 \pm 10$ & ns & 375 & 358 \\
\hline Claustrum & $432 \pm 32$ & $442 \pm 27$ & ns & 815 & 804 \\
\hline - Insular claustrum & $237 \pm 19$ & $241 \pm 16$ & ns & 447 & 438 \\
\hline - Prepiriform claustrum & $194 \pm 14$ & $201 \pm 13$ & ns & 366 & 365 \\
\hline Amygdala & $397 \pm 43$ & $405 \pm 22$ & ns & 749 & 736 \\
\hline - Basal nucleus & $113 \pm 15$ & $116 \pm 8$ & ns & 213 & 211 \\
\hline - Lateral nucleus & $189 \pm 20$ & $202 \pm 13$ & ns & 356 & 367 \\
\hline - Accessory basal nucleus & $82 \pm 10$ & $76 \pm 6$ & ns & 155 & 138 \\
\hline - Central nucleus & $13 \pm 1$ & $11 \pm 1$ & ns & 25 & 20 \\
\hline Nucleus accumbens & $244 \pm 23$ & $182 \pm 13$ & 0.050 & 460 & 331 \\
\hline Substantia nigra & $98 \pm 6$ & $88 \pm 4$ & ns & 185 & 160 \\
\hline Magnocellular basal complex & $84 \pm 8$ & $81 \pm 5$ & ns & 158 & 147 \\
\hline Lateral geniculate body & $80 \pm 5$ & $77 \pm 4$ & ns & 151 & 140 \\
\hline Inferior olive & $62 \pm 2$ & $59 \pm 4$ & ns & 117 & 107 \\
\hline Cerebellum & $31,779 \pm 1,304$ & $31,133 \pm 1,397$ & ns & 59,959 & 56,605 \\
\hline - Cerebellar cortex (calculated) & 24,715 & 24,811 & ns & 46,632 & 45,111 \\
\hline - Molecular layer & $12,623 \pm 443$ & $12,885 \pm 758$ & ns & 23,816 & 23,427 \\
\hline - Granule cell layer & $12,092 \pm 611$ & $11,926 \pm 474$ & ns & 22,815 & 21,684 \\
\hline - Cerebellar white matter & $6,700 \pm 380$ & $6,005 \pm 323$ & ns & 12,641 & 10,918 \\
\hline - Cerebellar nuclei & $364 \pm 34$ & $317 \pm 21$ & ns & 686 & 576 \\
\hline - Dentate nucleus & $244 \pm 14$ & $232 \pm 13$ & ns & 511 & 422 \\
\hline
\end{tabular}

*Statistical significance controlled for brain weight and brain weight decrease during dehydration (\%) entered as covariate. $\mathrm{ns}=$ not significant. Volume $\left(\mathrm{mm}^{3}\right)$ corrected for shrinkage: autism, $47 \%$; control, $45 \%$. 
Table 3 Total number of neurons per region and neuronal numerical density in 15 structures and 16 cytoarchitectonic subdivisions in examined brain hemisphere of individuals with autism and control subjects*

\begin{tabular}{|c|c|c|c|c|c|c|}
\hline \multirow{2}{*}{$\begin{array}{l}\text { Structure/cytoarchitectonic } \\
\text { subdivision }\end{array}$} & \multicolumn{3}{|c|}{ Total number of neurons per region } & \multicolumn{3}{|c|}{ Neuronal numerical density $\left(\mathrm{N} / \mathrm{mm}^{3}\right)$} \\
\hline & Autism & Control & $p<$ & Autism & Control & $p<$ \\
\hline Putamen & $61,675,039$ & $65,111,021$ & ns & 23,749 & 27,531 & 0.041 \\
\hline Caudate nucleus & $54,693,459$ & $49,292,390$ & ns & 25,958 & 28,542 & ns \\
\hline Thalamus & $47,403,083$ & $49,291,830$ & ns & 15,645 & 16,436 & ns \\
\hline Cornu Ammonis (CA) & $14,812,043$ & $15,047,614$ & ns & 24,769 & 24,955 & ns \\
\hline - CA1 & $11,575,341$ & $11,533,806$ & ns & 26,368 & 26,699 & ns \\
\hline - CA2 & $1,051,901$ & $1,152,120$ & ns & 32,872 & 32,003 & ns \\
\hline - CA3 & $1,054,780$ & $1,124,862$ & ns & 23,972 & 24,997 & ns \\
\hline - CA4 & $1,130,021$ & $1,236,826$ & ns & 13,453 & 13,897 & ns \\
\hline Claustrum & $12,351,088$ & $12,917,584$ & ns & 28,590 & 29,225 & ns \\
\hline - Insular claustrum & $6,576,940$ & $6,729,652$ & ns & 27,751 & 27,924 & ns \\
\hline - Prepiriform claustrum & $5,774,148$ & $6,187,932$ & $\mathrm{~ns}$ & 29,764 & 30,786 & ns \\
\hline Entorhinal cortex (EC) & $11,878,538$ & $12,915,740$ & ns & 23,997 & 27,077 & ns \\
\hline - EC Islands & 813,252 & $1,023,270$ & $\mathrm{~ns}^{\dagger}(0.013)$ & 21,401 & 24,364 & ns \\
\hline$-E C I I I$ & $5,553,881$ & $6,071,044$ & ns & 21,866 & 24,881 & 0.021 \\
\hline$-E C V$ & $1,871,129$ & $2,008,421$ & ns & 31,185 & 32,394 & ns \\
\hline$-\mathrm{EC} \mathrm{VI}$ & $3,640,276$ & $3,813,005$ & ns & 25,456 & 29,558 & ns \\
\hline Amygdala & $9,819,741$ & $11,138,599$ & ns & 24,735 & 27,503 & ns \\
\hline - Basal nucleus & $2,821,429$ & $3,154,350$ & ns & 24,968 & 27,193 & ns \\
\hline - Lateral nucleus & $4,609,751$ & $5,544,098$ & ns & 24,390 & 27,446 & 0.017 \\
\hline - Accesory basal nucleus & $2,046,439$ & $2,109,385$ & ns & 24,957 & 27,755 & ns \\
\hline - Central nucleus & 342,122 & 330,766 & ns & 26,317 & 30,070 & ns \\
\hline Nucleus accumbens & $8,078,093$ & $7,285,654$ & ns & 33,107 & 40,031 & 0.018 \\
\hline Lateral geniculate body & $1,493,426$ & $1,392,966$ & ns & 18,668 & 18,090 & ns \\
\hline Globus pallidus & $1,277,936$ & $1,312,262$ & ns & 2,092 & 2,339 & ns \\
\hline - External globus pallidus & 899,307 & 904,365 & ns & 2,183 & 2,485 & ns \\
\hline - Internal globus pallidus & 378,629 & 407,897 & ns & 1,903 & 2,071 & ns \\
\hline Dentate nucleus & 970,440 & 918,809 & ns & 3,977 & 3,960 & ns \\
\hline Magnocellular basal complex & 768,415 & 790,893 & ns & 9,148 & 9,764 & ns \\
\hline Inferior olive & 793,002 & 716,895 & ns & 12,790 & 12,151 & ns \\
\hline Substantia nigra & 744,247 & 707,228 & ns & 7,594 & 8,037 & ns \\
\hline Cerebellum (Purkinje cells) & $12,060,920$ & $16,003,095$ & 0.0001 & 488 & 645 & 0.0024 \\
\hline
\end{tabular}

*Controlled for log age, brain weight, post-mortem interval, days of fixation, and percentage of brain weight loss during dehydration entered as covariates. ${ }^{\dagger}$ The total number of neuronal deficit (by $20 \% ; p<0.013$ ) in stellate neuron islands in the entorhinal cortex was not significant only when log age, brain weight, post-mortem interval, and days of fixation were entered as covariates.

of 12 examined subjects in the affected group (42\%), the number was less than in this control subject. The total number of Purkinje cells was less in all individuals with autism than the average number in the control group. The numerical density of Purkinje cells was also significantly less $(p<0.0024)$ in affected subjects $\left(488 / \mathrm{mm}^{3}\right)$ than in control subjects $\left(645 / \mathrm{mm}^{3}\right)(-24.4 \%)$.

The absence of a significant correlation between age and the total number or numerical density of neurons $\left(\mathrm{N} / \mathrm{mm}^{3}\right)$ in the cohort with autism suggests that the detected neuronal deficits do not decrease greatly, if at all, from 4 to 60 years of age among subjects diagnosed with autism. However, examination of only three subjects with autism 52 to 60 years of age and of three control subjects 51-64 years of age is not favorable for detection of aging-associated neuronal loss.

\section{Discussion}

Estimates of the volume of 38 brain subdivisions, neuronal number per cubic millimeter, and neuronal number per 

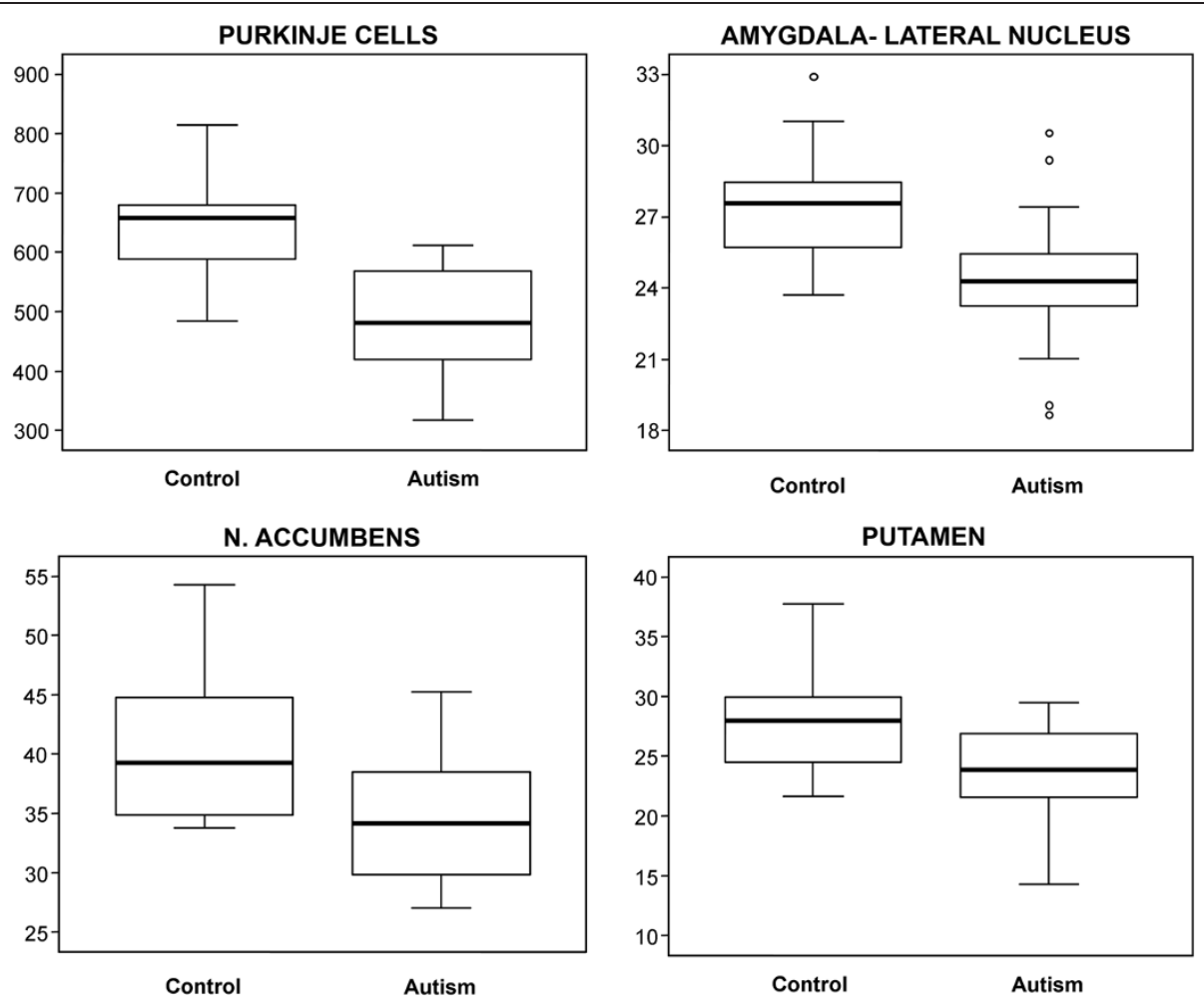

Figure 4 Numerical density of Purkinje cells, and neurons in the lateral nucleus in the amygdala, nucleus accumbens and in the putamen. Box plots demonstrate the considerable differences between the median numerical density (thick line within the box) of Purkinje cells $\left(\mathrm{n} / \mathrm{mm}^{3}\right)$, and between the number of neurons in the lateral nucleus in the amygdala, nucleus accumbens and putamen (thousands/mm $\left.{ }^{3}\right)$ in the group with autism and control groups. In the majority of individuals diagnosed with autism, the numerical density of neurons is less than the median numerical density in the control group. The upper and lower boundaries of each box represent the 75th and 25th percentiles of the data, respectively; the depth of the box thus represents the interquartile range (IQR). The "whisker" above the box is the maximum value unless any data point lies more than 1.5 times the IQR above the 75th percentile, in which case the maximum value is the 75 th percentile plus 1.5 times the IQR, and the points outside it (outliers) are indicated by circles. The lower whisker and outliers are computed analogously.

specific cytoarchitectonic subdivision revealed that significant alterations in the group of subjects with autism are limited to the caudate nucleus and nucleus accumbens in the striatum, the lateral nucleus in the amygdala, and Purkinje cells in the cerebellum. The pattern of developmental alterations of the brain structures' volume and number of neurons limited to these few brain regions is consistent with several morphometric and MRI studies, but is in striking contrast to the abnormal trajectories of neuronal soma volume growth detected in 14 of 16 examined brain structures of 4- to 8-year-old children with autism. The number of regions with a significant deficit of neuronal soma volume decreases to three in autistic teenagers/young adults and has been observed in only four regions in 36- to 60-year-old autistic individuals [35]. This disparity between the limited alterations of brain structures' volume and number of neurons but the common neuronal volume deficit in children and an increase of perikaryon volume in autistic teenagers and adults suggests a separation of mechanisms controlling developmental changes of the number of neurons and of brain structure volume from mechanisms that control brain region-specific trajectories of neuron growth. These two studies suggest that some neuronal populations-Purkinje cells, neurons in the caudate nucleus and accumbens, and in the lateral nucleus of the amygdala-are affected by both mechanisms.

\section{Cerebellum}

Studies of the cerebellum of individuals diagnosed with autism provide inconsistent results, including smaller cerebellar hemispheres [45,46] and smaller vermis [47-49] as well as increased cerebellar volume or volume proportional to brain size [50]. The study by Fatemi et al. [25] of the cerebellum of five males with autism with a mean age of 25.2 years and of five age-matched controls revealed a 24\% decrease in mean Purkinje cell size but no differences in Purkinje cell densities. The study of the cerebellum of a 16-year-old female diagnosed with autism and severe intellectual deficit showed no alterations in the cerebellum 
[24]. Several reports suggested associations between the size of the vermis and attention deficits, enhanced stereotypic behavior, and reduced exploration in autism [51-53].

Our review of the literature indicates that the current study is the first to report on the total number of Purkinje cells and cerebellar global volumetry in autism. The study revealed a significantly lower total number of Purkinje cells in the cerebellum in the group of subjects who were diagnosed with autism (12.1 million per examined hemisphere, and 24.2 million calculated for entire cerebellum) than in control subjects (16.0 and 32.0 million, respectively). The total number of Purkinje cells in the entire cerebellum of control subjects in our cohort 4-64 years of age is comparable to estimates reported by other authors, with some modifications due to age and methods: 28.5 million in 10 control males, 28-84 years of age [54]; 28.6 million in 19 control subjects, 19-84 years of age [55], 29.8 million in 10 controls, 21-65 years of age [56]; and from 19.7 to 27.0 million in four controls, 41-84 years old [57].

Autism is associated with significant inter-individual differences in the number of Purkinje cells, but a smaller number of Purkinje cells was observed in the majority of 29 individuals diagnosed with autism (reviewed by Palmen et al., [58]). Recently, eight subjects with autism and seven control subjects from our cohort of 14 autistic and 14 control subjects were examined by Skefos et al. [59] to detect links between structural alteration of four cerebellar subdivisions and functional abnormalities typical for autism. The authors examined the crus I and II in the posterior lobe reciprocally connected with prefrontal cortical networks that modulate social behavior, and the hemispheric portion of lobules IV-VI known as a primary sensorimotor processing area. The lower Purkinje cell density in these regions supports the hypothesis that abnormal Purkinje cell density may contribute to selected clinical features of the autism phenotype. The reduced number of Purkinje cells and dysplastic changes in lobule X may have a direct contribution to alterations of eye movement in subjects with autism [60]. Some studies suggest that a regional decrease in the number of Purkinje cells may be the result of prenatal loss of Purkinje cells [27]. Some inter-individual differences in the number of Purkinje cells reported in the past might be related to treatment of epilepsy-associated loss of Purkinje cells [61-64] and/or pre-mortem changes related to the mechanism of death. Signs of structural developmental alterations coincide with a $40 \%$ decrease in the expression of glutamic acid decarboxylase 67 (GAD67) mRNA in autistic subjects and an increased GABAergic feed-forward inhibition to Purkinje cells by basket cells. These data suggest a disruption in the timing of Purkinje cell firing and altered inhibition of the cerebellar nuclei, which could directly affect cerebello- cortical output, leading to changes in motor behavior and cognition [65].

In the examined cohort, the difference between volumes of the cerebellar hemisphere in the group with autism and control groups $\left(31,779 \mathrm{~mm}^{3}\right.$ and $31,133 \mathrm{~mm}^{3}$, respectively) was not significant. This volume reflects a $45 \%$ reduction of brain weight during dehydration in ethyl alcohol of the brains of control subjects and a $47 \%$ reduction in individuals diagnosed with autism. The volume calculated for both cerebellar hemispheres of control subjects and corrected for $45 \%$ shrinkage is equal to $113.2 \mathrm{~mm}^{3}$ and is comparable to $124.8 \mathrm{~cm}^{3}$ in the study by Andersen et al. [55] of 19 control males from 19 to 84 years of age.

This study found a significant-25\%-deficit in the number of Purkinje cells in the absence of significant differences between affected and control cohorts in the volume of the molecular and granule cell layer, cerebellar white matter, or total volume of cerebellar nuclei. Previous study revealed severe Purkinje cell soma volume deficits in the range of $31 \%$ in 4- to 8 -year-olds and of $23 \%$ in 29- to 60-year-olds [35]. These findings, and the absence of abnormalities in the number and distribution of GABAergic basket and stellate interneurons in the cerebellar molecular layer reported by Whitney et al. [27], suggest that Purkinje cells are the major target of the genetic and/or epigenetic factors that define the contribution of Purkinje cells' pathology to the autistic phenotype.

\section{Striatum}

In our control cohort the volume of the caudate nucleus was estimated as $1,727 \mathrm{~mm}^{3}$, versus $2,212 \mathrm{~mm}^{3}$ in Kreczmanski et al. [66] study, and 2,043 $\mathrm{mm}^{3}$ in Bogerts study [67] (with Kreczmanski's et al. correction for shrinkage). The volume of the putamen was $2,365 \mathrm{~mm}^{3}$ in our material, 2,713 $\mathrm{mm}^{3}$ in Kreczmanski et al. study [66], and 2,979 $\mathrm{mm}^{3}$ in Bogerts study [67] (with Kreczmanski's correction for shrinkage). The volume of the nucleus accumbens was estimated as $182 \mathrm{~mm}^{3}$ in this study, $204 \mathrm{~mm}^{3}$ in Kreczmanski et al.[66], $147 \mathrm{~mm}^{3}$ in Lauer et al. [68] (with Kreczmanski's shrinkage factor), and $138 \mathrm{~mm}^{3}$ in Pakkenberg study based on examination of $4-\mu \mathrm{m}$ thick paraffin sections [69].

The volume of the caudate nucleus was significantly greater in the group with autism than in the control group $\left(2,107 \mathrm{~mm}^{3}\right.$ and $1,727 \mathrm{~mm}^{3}$, respectively; $\left.\mathrm{p}<0.036\right)$. Several MRI studies of patients with autism have revealed increased volumes of the basal ganglia [20,70-72] and a correlation between caudate nucleus volumes and repetitive-behavior scores [70,71]. A direct relationship between repetitive behaviors and right caudate nucleus volume was reported in an cohort of 17-55 years of age patients diagnosed with autism [71], but not in a cohort including children [73]. Brain size increases to the age 
of 5 years, whereas the volume of the caudate grows until late childhood $[18,74]$ and decreases during adulthood [73,75]. Regional reduction of the caudate nucleus head volume by up to $50 \%$ and the presence of foci of tissue loss, detected by repeated scanning with highresolution MRI and use of continuum mechanical tensor maps, were interpreted as evidence of the pruning process at 9-13 years of age in control subjects [74]. The lack of differences on postmortem evaluation of caudate nucleus volume between 4- to 8-year-old autistic and age-matched control subjects, but the significantly larger caudate nucleus and nucleus accumbens and insignificantly higher (by $11 \%$ ) total number of neurons in these structures in 9- to 60-year-old subjects diagnosed with autism in our cohort may indicate timely pruning in the control group, but regionally defective pruning in affected subjects, as postulated by Voelbel et al. [76].

A subcomponent of changes in the striatum is the significant deficit in the volume of neuronal soma in the nucleus accumbens (34\%) and caudate nucleus (22\%) in 4- to 8-year-old subjects with autism, but not in affected adolescents or adults [35]. These data suggest the deregulation of mechanisms that control the number and volume of neurons and the total volume of the caudate nucleus and nucleus accumbens. Correlations between MRI-detected alterations within the striatum and the severity of clinical changes $[70,71]$ imply that these cellular alterations may contribute to stereotyped and ritualistic behaviors in autism. The nucleus accumbens, which is considered a mixed structure with elements of the striatum and the amygdala [77], processes information about reward value and availability and is involved in rewardrelated behaviors [78]. Projections of nucleus accumbens neurons to the ventral pallidum translate reward information into motivated action [79]. A significantly larger nucleus accumbens (by $34 \%, p<0.050$ ) appears to be another deregulated component of striatal circuits that may enforce repetitive behaviors in autism.

The striatum alterations observed in idiopathic autism resemble some structural and functional changes observed in fragile X syndrome (FXS). Autism is diagnosed in 25$30 \%$ of individuals diagnosed with FXS [80-84]. Hatton et al. [82] suggested that lower levels of fragile X mental retardation protein (FMRP) expression contribute to autistic behavior and intellectual deficits in children with FXS. Gothelf et al. [85] revealed a correlation between lower levels of FMRP, behavioral alterations, and alterations of the size of some brain subdivisions, including increased size of the caudate nucleus but decreased size of the amygdala, superior temporal gyrus, and posterior cerebellar vermis in FXS. A 75\% reduction of FMRP expression in vermis and a $50 \%$ reduction in the superior frontal cortex (BA9) in adults with idiopathic autism may contribute to both structural abnormalities and the autistic phenotype [86].

\section{Amygdala}

Neuropathological studies [87] and results of structural $[10,88]$ and functional [89] neuroimaging indicate that the amygdala is affected in autism. The study by Schumann and Amaral [31] of the amygdala in nine brains of individuals with autism 10-44 years of age and 10 brains of age-matched controls did not reveal a difference in the number of neurons in the basal, accessory basal, and central nucleus. However, the authors reported 13\% fewer neurons in the lateral nucleus (3.47 million in the autistic group and 4.00 million in the control group; $p<0.05)$ and $12 \%$ fewer neurons in the entire amygdala (10.74 million in the affected group and 12.21 million in the control group; $p<0.05)$. The significantly $(p<0.017)$ reduced numerical density of neurons in the lateral nucleus in the amygdala of subjects with autism in our cohort of 14 subjects $4-60$ years of age $\left(24,390 / \mathrm{mm}^{3}\right.$ in the affected group and $27,446 / \mathrm{mm}^{3}$ in the control group) and the absence of significant changes in other amygdala subdivisions in these subjects confirm the selective developmental abnormality of the lateral nucleus. In our study, the total number of neurons in the lateral nucleus in subjects with autism was also less (by 17\%) $(4,609,751)$ than in the control group $(5,544,098)$, but after control for five covariates, the difference was found to be not significant. Differences in tissue preservation, the age of examined subjects, and selection of only epilepsy-free males in the study by Schumann and Amaral [31] may contribute to some differences in the number of neurons reported, but the general pattern of alterations detected in both studies is similar.

Reduced neuronal density in the absence of a change in the total number of neurons in the amygdala may suggest the involvement of non-neuronal factors, including glia. Ahlsen et al. [90] reported increased levels of GFAP, a marker of astroglial activation, in the CSF in subjects with autism. There are no data about astrocytosis within the amygdala, but Laurence and Fatemi [91] demonstrated by Western blots an increased level of GFAP in superior frontal cortex (BA9; by 45\%), parietal cortex (BA40; by 75\%) and in the cerebellum (by $49 \%$ ) in subjects with autism. Vargas et al. [92] reported signs of selective activation of astroglia and microglia in several brain regions of subjects with autism. A new concept of tripartite synapses with astrocytes controlling synapses formation and function [93] and signs of astrocytosis may suggest a glial contribution to structural and functional changes in the brains of subjects diagnosed with autism.

Individuals with autism display deficits of social behavior, including abnormalities in social reciprocity, difficulties in the use of eye contact, and deficits in social motivation [1]. The theory of mind proposes that the amygdala is one of several brain regions that are parts of the social brain and are necessarily abnormal in autism [89]. Moreover, the amygdala controls behavioral responses such as the 
fear and anxiety observed in $84 \%$ of children with autism $[94,95]$. The alterations in the amygdala detected in morphometric studies and in MRI-based volumetry suggest that developmental abnormalities of the amygdala may contribute to the autistic phenotype. Some differences of the estimated total number of neurons in the lateral nucleus in the amygdala in the control group in Schumann and Amaral [4] study (4.0 million), Kreczmanski et al. [66] (4.43 million) and 5.54 million in our study reflect mainly technical differences and in part interindividual differences.

\section{Neocortex and archicortex}

Stoner et al. study [96] revealed patches of disorganization in the prefrontal and temporal cortices in a majority of children diagnosed with autism. This focal disruption of cortical architecture suggests dysregulation of layer formation and layer-specific neuronal differentiation at prenatal developmental stages. Van Kooten et al. [32] showed significant reductions in neuron densities in layer III, total number of neurons in layers III, V, and VI in the fusiform gyrus, but none of these alterations were found in the primary visual cortex or the whole cerebral cortex. This study provides insight about the cellular basis of abnormalities in face perception in autism. Several other reports indicated the absence of alterations in the number of neurons in the cerebral cortex [97]; in the superior frontal cortex [98]; in the BA44 and BA45 [28]; and in the frontoinsular cortex [23]. A study of von Economo neurons revealed no significant difference in the mean number of these neurons in the frontoinsular cortex [26] and in the anterior cingulate cortex (BA24) [33]. A study of the frontoinsular cortex in four subjects with autism, (4-11 years of age) and three control (4-14 years of age) subjects revealed an increase in the ratio between von Economo neurons and pyramidal neurons, but the difference between the number of von Economo neurons in subjects with autism and control subjects fell short of statistical significance, and the total estimated number of pyramidal neurons did not reveal a significant difference [23].

Our study of the archicortex of subjects with autism revealed focal microdysgenesis with selective deficits of stellate neurons in irregular smaller islands in the second layer of the entorhinal cortex in 23- and 60-year-old affected subjects [36]. The reduced total number of neurons in the islands and in the third layer of the entorhinal cortex suggests developmental abnormalities within the perforant pathway projecting to the dentate gyrus and Ammons horn. These alterations may affect memorization and emotional behavior [99]. Similar deficits of stellate neurons in islands and a thicker molecular layer in the entorhinal cortex of subjects diagnosed with schizophrenia were described as evidence of defects of migration of neurons to their target destination during development [100,101].

\section{Developmental deficit and loss of neurons in autism}

For much of the history of postmortem studies of ASD pathology, brain abnormalities have been viewed as static [102], but the regression observed in $15-62 \%$ of autism cases has been linked to neurodegeneration and neuronal loss [103]. However, morphological markers of neurodegeneration have been reported only sporadically, including cytoplasmic homogenous inclusions in Purkinje cells in affected child [98], Purkinje and granule cells' mineralization [87], and neurofibrillary degeneration in a 24-year-old autistic female with self-injurious behavior including head-banging [104].

The Fatemi et al. [105] review demonstrates agreement on a Purkinje cells deficit in the cerebellum of individuals diagnosed with autism. The lower number of Purkinje cells in subjects diagnosed with autism is considered mainly the result of the loss of these cells before 30 weeks' gestation [87], but postnatal Purkinje cell death accompanied by astrocytosis has been also reported [98]. In some cases, loss of Purkinje cells might be the result of chronic treatment with anti-epileptogenic drugs such as phenytoin $[61,62]$. The lack of correlation between the number of Purkinje cells and age in the examined cohort of autistic subjects 4-60 years of age suggests that the $25 \%$ deficit of Purkinje cells is mainly a developmental fetal defect, as postulated by Kemper and Bauman [87], but the combination of prenatal deficit and postnatal loss cannot be excluded.

Comparison of the total number of neurons in the Ammons horn in this control group and control groups in other reports reveals differences related to the methods of tissue preservation and morphometric evaluation, and the age of examined cohorts. Our study revealed that the total numbers of neurons in the CA1, CA2/3, and CA4 sectors of control subjects 4-64 years of age were 11.5, 2.1, and 1.1 million, respectively. The numbers of neurons in the CA1, CA2/3, and CA4 sectors in control subjects 21-56 years of age were determined to be 14.7, 2.7, and 2.12 million, respectively [106]; for 47- 85 years of age, 16.0, 2.7, and 2.0 million, respectively [107]; and for 72-96 years of age, 6.2, 1.7, and 0.7 million, respectively [108]. Similar, age-associated differences are observed in the substantia nigra, with the total number of neurons of 707,000 in our control group, and of 550,000 neurons in 71- to 87-year-old control subjects in the Pakkenberg et al. study [109].

Several studies have revealed neuronal pathology affecting cytoplasmic organelles and possibly sustaining functional abnormalities in autism, but there is no direct evidence that they cause significant neuronal death. An abnormal electron transfer chain in neuronal mitochondria may alter energy generation, metabolism, and cell structure and function; however, these changes prevail only in children, not in adults $[110,111]$. An imbalance 
between mitochondria biogenesis and degradation increases the mass of compromised mitochondria in neurons in the temporal cortex, but this pathology was also demonstrated only in young individuals diagnosed with ASD [112]. Currently, there is no evidence that the elevated oxidative stress detected as an increase of 3 -nitrotyrosine in the cortex, cerebellum, and pons of subjects with autism [113] and the two-fold increase of DNA oxidation in the frontal and temporal cortex and in the cerebellum [114] cause neuronal loss. In idiopathic autism and autism associated with dup15, a self-enhancing cascade of pathological changes alters amyloid precursor protein (APP) metabolism, and increases cytoplasmic accumulation of amino-terminally truncated amyloid- $\beta$, which is the source of reactive oxygen species and which increases the formation of lipid peroxidation products. These changes enhance amyloid- $\beta$ deposition and sustain the cascade of changes contributing to metabolic and functional impairments in neurons $[115,116]$. These alterations may contribute to activation of astrocytes and microglial cells, enhanced astrocytosis, and astrocytes' death [115]; however, the potential neuronal loss associated with this pathology appears to be hidden within a range of interindividual differences and was not detected as an age-associated correlate in the examined cohort.

\section{Conclusions}

The alterations in regional volume and neuron number in only a few brain structures in the autism cohort we studied here contrast with the brain region-specific developmental deficits in the volumes of neuronal soma detected in almost all examined brain regions as shown in our previous report [35]. This disparity may reflect a separation of mechanisms controlling developmental changes in neuronal number and brain structures' volume from mechanisms controlling brain region-specific trajectories of neuronal growth. However, the severe deficit of Purkinje cell, and significant alterations of the volume of striatum and amygdala subdivisions and their neuronal number, combined with prominent alterations of trajectories of neuronal growth, suggest that developmental abnormalities of these brain structures are products of mechanisms controlling both structures' size and neuronal number and volume. This duplication of mechanisms controlling the different types of developmental abnormalities in a few brain regions may amplify their contribution to the repetitive behaviors and social and communication deficits observed in autism.

This study increases the coherence of comparative stereological characteristics by the assessment of 38 brain structures and cytoarchitectonic subdivisions in a relatively large cohort of subjects diagnosed with autism using one standard of tissue preservation, embedding, sectioning, and staining and unbiased stereological estimates. The consistency of the characteristics of this cohort is enhanced by our previous analysis of qualitative developmental abnormalities [36], the study of trajectories of neuronal soma changes throughout the lifespan [35], and the application of a major portion of this material for unbiased stereological studies of developmental abnormalities in the cerebral cortex [23,28,32], cerebellum [59], and brainstem [34].

\section{Consent}

This postmortem study has been performed using anonymous coded brain tissue samples. Selected clinical records were extracted from the anonymous coded Autism Tissue Program - Autism Speaks database by authorized project PI.

\section{Competing interests}

The authors declare that they have no competing interests.

\section{Authors' contributions}

JW and WTB designed the project, coordinated the efforts of several groups of researchers and drafted the manuscript. MF participated in the design of the study and performed the statistical analyses. IK, KN, SYM, HI and JW performed morphometric studies, built databases supporting this study, and helped draft the manuscript. ILC, EL, and TW contributed to clinical and neuropathological evaluation and integration of clinicopathological data. All authors read and approved the final manuscript.

\section{Acknowledgments}

This study was supported in part by funds from the New York State Office for People With Developmental Disabilities, a grant from the Department of Defense Autism Spectrum Disorders Research Program (AS073234, J.W., T.W.), and a grant from Autism Speaks (Princeton, NJ; J.W.). Tissue and clinical records acquisition was coordinated by The Autism Tissue Program (Princeton, NJ; Director: Jane Pickett, Ph.D.). The tissue was obtained from the Harvard Brain Tissue Resource Center, Belmont, MA, supported in part by PHS grant number R24-MH 068855; the Brain and Tissue Bank for Developmental Disorders of the National Institute of Child Health and Human Development at the University of Maryland; and the Brain and Tissue Bank for Developmental Disabilities and Aging at the New York State Institute for Basic Research in Developmental Disabilities, Staten Island, NY. We thank Mrs. Maureen Marlow for manuscript editing, Drs. Helmut Hainsen and Christoph Schmitz for help in implementation of the celloidin protocol, and Mrs. Jadwiga Wegiel, Cathy Wang, and En Wu Zheng for histology. We are deeply indebted to the families of our donors who have made this study possible. The authors declare that they have no conflict of interest.

\section{Author details}

'Department of Developmental Neurobiology, NYS Institute for Basic Research in Developmental Disabilities, 1050 Forest Hill Road, Staten Island, NY 10314, USA. ²Department of Infant Development, NYS Institute for Basic Research in Developmental Disabilities, 1050 Forest Hill Road, Staten Island, NY 10314, USA. ${ }^{3}$ Department of Psychology, NYS Institute for Basic Research in Developmental Disabilities, 1050 Forest Hill Road, Staten Island, NY 10314, USA. ${ }^{4}$ Department of Neurology, Psychiatry and Pathology, New York University School of Medicine, 450 East 29th Street, Room 802, New York, NY 10016, USA. ${ }^{5}$ Department of Human Genetics, NYS Institute for Basic Research in Developmental Disabilities, 1050 Forest Hill Road, Staten Island, NY 10314, USA.

Received: 30 July 2014 Accepted: 9 September 2014

Published online: 18 September 2014 


\section{References}

1. Lord C, Risi S, Lambrecht L, Cook EH Jr, Leventhal BL, DiLavore PC, Pickles A, Rutter M: The autism diagnostic observation schedule-generic: a standard measure of social and communication deficits associated with the spectrum of autism. J Autism Dev Disord 2000, 30:205-223.

2. Ozonoff S: Editorial perspective: autism spectrum disorders in DSM-5-an historical perspective and the need for change. J Child Psychol Psychiatry 2012, 53:1092-1094.

3. Fombonne E, Roge B, Claverie J, Courty S, Fremolle J: Microcephaly and macrocephaly in autism. J Autism Dev Disord 1999, 29:113-119.

4. Courchesne E, Carper R, Akshoomoff N: Evidence of brain overgrowth in the first year of life in autism. JAMA 2003, 290:337-344.

5. Dementieva YA, Vance DD, Donnelly SL, Elston LA, Wolpert CM, Ravan SA, DeLong GR, Abramson RK, Wright HH, Cuccaro ML: Accelerated head growth in early development of individuals with autism. Pediatr Neurol 2005, 32:102-108.

6. Dissanayake C, Bui QM, Huggins R, Loesch DZ: Growth in stature and head circumference in high-functioning autism and asperger disorder during the first 3 years of life. Dev Psychopathol 2006, 18:381-393.

7. Dawson G, Munson J, Webb SJ, Nalty T, Abbott R, Toth K: Rate of head growth decelerates and symptoms worsen in the second year of life in autism. Biol Psychiatry 2007, 61:458-464

8. Courchesne E, Karns CM, Davis HR, Ziccardi R, Carper RA, Tique ZD, Hisum HJ, Moses P, Pierce K, Lord C, Lincoln AJ, Pizzo S, Schreibman L, Hass RH Akshoomoff NA, Courchesne RY: Unusual brain growth patterns in early life in patients with autistic disorder: an MRI study. Neurology 2001, 57:245-254.

9. Carper RA, Moses P, Tigue ZD, Courchesne E: Cerebral lobes in autism: early hyperplasia and abnormal age effects. Neurolmage 2002, 16:1038-1051.

10. Sparks BF, Friedman SD, Shaw DW, Aylward EH, Echelard D, Artru AA, Maravilla KR, Giedd JN, Munson J, Dawson G, Dager SR: Brain structural abnormalities in young children with autism spectrum disorder. Neurology 2002, 59:184-192.

11. Hazlett HC, Poe M, Gerig G, Smith RG, Provenzale J, Ross A, Gilmore J, Piven J: Magnetic resonance imaging and head circumference study of brain size in autism: birth through age 2 years. Arch Gen Psychiatry 2005, 62:1366-1376

12. Redcay E, Courchesne E: When is the brain enlarged in autism? A meta-analysis of all brain size reports. Biol Psychiatry 2005, 58:1-9.

13. Kosaka H, Omori M, Munesue T, Ishitobi M, Matsumura Y, Takahashi T, Narita K, Murata T, Saito DN, Uchiyama H, Morita T, Kikuchi M, Mizukami K, Okazawa H, Sadato N, Wada Y: Smaller insula and inferior frontal volumes in young adults with pervasive developmental disorders. Neurolmage 2010, 50:1357-1363.

14. Raznahan A, Wallace GL, Antezana L, Greenstein D, Lenroot R, Thurm A, Gozzi M, Spence S, Martin A, Swedo SE, Giedd JN: Compared to what? Early brain overgrowth in autism and the perils of population norms. Biol Psychiatry 2013, 74:563-575.

15. Cohen MM Jr: Mental deficiency, alterations in performance, and CNS abnormalities in overgrowth syndromes. Am J Med Genet C: Semin Med Genet 2003, 117C:49-56.

16. Betancur C: Etiological heterogeneity in autism spectrum disorders: more than 100 genetic and genomic disorders are still counting. Brain Res 2011, 1380:42-77.

17. Wegiel J, Schanen NC, Cook EH, Sigman M, Brown WT, Kuchna I, Nowicki K, Wegiel J, Imaki H, Ma SY, Marchi E, Wierzba Bobrowicz T, Chauhan A, Chauhan V, Cohen IL, London E, Flory M, Lach B, Wisniewski T: Differences between the pattern of developmental abnormalities in autism associated with duplications 15q11.2-q13 and idiopathic autism. J Neuropathol Exp Neurol 2012, 71:382-397.

18. Caviness VS Jr, Kennedy DN, Richelme C, Rademacher J, Filipek PA: The human brain age 7-11 years: a volumetric analysis based on magnetic resonance images. Cereb Cortex 1996, 6:726-736.

19. Piven J, Arndt S, Bailey J, Andreasen N: Regional brain enlargement in autism: a magnetic resonance imaging study. J Am Acad Child Adolesc Psychiatry 1996, 35:530-536.

20. Herbert MR, Ziegler DA, Deutsch CK, O'Brien LM, Lange N, Bakardjiev A, Hodgson J, Adrien KT, Steele S, Makris N, Kennedy D, Harris GJ, Caviness VS Jr: Dissociations of cerebral cortex, subcortical and cerebral white matter volumes in autistic boys. Brain 2003, 126:1182-1192.
21. Carper RA, Courchesne E: Localized enlargement of the frontal cortex in early autism. Biol Psychiatry 2005, 57:126-133.

22. Courchesne E, Mouton PR, Calhoun ME, Semendeferi K, Ahrens-Barbeau C, Hallet MJ, Barnes CC, Pierce K: Neuron number and size in prefrontal cortex of children with autism. JAMA 2011, 306:2001-2010.

23. Santos M, Uppal N, Butti C, Wicinski B, Schmeidler J, Giannakopoulos P, Heinsen H, Schmitz C, Hof PR: Von Economo neurons in autism: a stereologic study of the frontoinsular cortex in children. Brain Res 2011, 1380:206-217

24. Guerin P, Lyon G, Barthelemy C, Sostak E, Chevrollier V, Garreau B, Lelord G: Neuropathological study of a case of autistic syndrome with severe mental retardation. Dev Med Child Neurol 1996, 38:203-211.

25. Fatemi SH, Halt AR, Realmuto G, Earle J, Kist DA, Thuras P, Merz A: Purkinje cell size is reduced in cerebellum of patients with autism. Cell Mol Neurobiol 2002, 22:171-175.

26. Kennedy DP, Semendeferi K, Courchesne E: No reduction of spindle neuron number in frontoinsular cortex in autism. Brain Cogn 2007, 64:124-129.

27. Whitney ER, Kemper TL, Rosene DL, Bauman ML, Blatt GJ: Density of cerebellar basket and stellate cells in autism: evidence for a late developmental loss of Purkinje cells. J Neurosci Res 2009, 87:2245-2254

28. Jacot-Descombes S, Uppal N, Wicinski B, Santos M, Schmeidler J, Giannakopoulos P, Heinsen H, Schmitz C, Hof PR: Decreased pyramidal neuron size in brodmann areas 44 and 45 in patients with autism. Acta Neuropathol 2012, 124:67-79.

29. Ritvo ER, Freeman BJ, Scheibel AB, Duong T, Robinson H, Guthrie D, Ritvo A: Lower Purkinje cell counts in the cerebella of four autistic subjects: initial findings of the UCLA-NSAC autopsy research report. Am J Psychiatry 1986, 143:862-866.

30. Kemper TL, Bauman M: Neuropathology of infantile autism. J Neuropath Exp Neurol 1998, 57:645-652

31. Schumann CM, Amaral DG: Stereological analysis of amygdala neuron number in autism. J Neurosci 2006, 26:7674-7679.

32. van Kooten IAJ, Palmen SJMC, von Cappeln P, Steinbusch HWM, Korr H, Heinsen H, Hof PR, van Engeland H, Schmitz C: Neurons in the fusiform gyrus are fewer and smaller in autism. Brain 2008, 131:987-999.

33. Simms ML, Kemper TL, Timbie CM, Bauman ML, Blatt GJ: The anterior cingulate cortex in autism: heterogeneity of qualitative and quantitative cytoarchitectonic features suggests possible subgroups. Acta Neuropathol 2009, 118:673-684

34. Kulesza RJ Jr, Lukose R, Stevens LV: Malformation of the human superior olive in autistic spectrum disorders. Brain Res 2011, 1367:360-371.

35. Wegiel J, Flory M, Kuchna I, Nowicki K, Ma SY, Imaki H, Wegiel J, Cohen IL, London E, Brown WT, Wisniewski T: Brain-region-specific alterations of the trajectories of neuronal volume growth throughout the lifespan in autism. Acta Neuropathol Comm 2014, 2:28.

36. Wegiel J, Kuchna I, Nowicki K, Imaki H, Wegiel J, Marchi E, Ma SY, Chauhan A, Chauhan V, Wierzba Bobrowicz T, de Leon M, Sain Louis LA, Cohen IL, London E, Brown WR, Wisniewski T: The neuropathology of autism: defects of neurogenesis and neuronal migration, and dysplastic changes. Acta Neuropathol 2010, 119:755-770.

37. Heinsen H, Arzberger T, Schmitz C: Celloidin mounting (embedding without infiltration) - a new, simple and reliable method for producing serial sections of high thickness through complete human brains and its application to stereological and immunohistochemical investigations. J Chem Neuroanat 2000, 20:49-59.

38. Lehéricy S, Hirsch EC, Cervera P, Hersch LB, Hauw J-J, Ruberg M, Agid Y: Selective loss of cholinergic neurons in the ventral striatum of patients with Alzheimer disease. Proc Natl Acad Sci U S A 1989, 86:8580-8584

39. Braak H, Braak E: Neuronal types in the striatum of man. Cell Tissue Res 1982, 227:319-342

40. Alheid GF, Heimer L, Switzer RC III: Basal Ganglia. In The Human Nervous System. Edited by Paxinos G. San Diego: Academic Press, Inc; 1990:483-582.

41. Schumann CM, Amaral DG: Stereological estimation of the number of neurons in the human amygdaloid complex. J Comp Neurol 2005, 491:320-329.

42. Amaral DG, Insausti R: Hippocampal Formation. In The Human Nervous System. Edited by Paxinos G. San Diego: Academic Press, Inc; 1990:711-755.

43. Braak H: Architectonics of the Human Telencephalic Cortex. New York: Springer Verlag; 1980. 
44. Duvernoy HM: The Human Hippocampus. München: J.P. Bergman Verlag; 1988:1-166.

45. Gaffney GR, Tsai LY, Kuperman S, Minchin S: Cerebellar structure in autism. Am J Dis Child 1987, 141:1330-1332.

46. Murakami JW, Courchesne E, Press GA, Yeung-Courchesne R, Hesselink JR: Reduced cerebellar hemisphere size and its relationship to vermal hypoplasia in autism. Arch Neurol 1989, 46:689-694.

47. Courchesne $E$, Yeung-Courchesne R, Press GA, Hesselink JR, Jernigan TL: Hypoplasia of cerebellar vermal lobules VI and VII in autism. N Engl J Med 1988, 318:1349-1354.

48. Hashimoto T, Tayama M, Murakawa K, Yoshimoto T, Miyazaki M, Harada M, Kuroda Y: Development of the brainstem and cerebellum in autistic patients. J Autism Dev Disord 1995, 25:1-18.

49. Ciesielski KT, Harris RJ, Hart BL, Pabst HF: Cerebellar hypoplasia and frontal lobe cognitive deficits in disorders of early childhood. Neuropsychologia 1997, 35:643-655.

50. Piven J, Saliba K, Bailey J, Arndt S: An MRI study of autism: the cerebellum revisited. Neurology 1997, 49:546-551.

51. Harris NS, Courchesne E, Townsend J, Carper RA, Lord C: Neuroanatomic contributions to slowed orienting of attention in children with autism. Brain Res. Cogn Brain Res 1999, 8:61-71.

52. Townsend J, Courchesne E, Covington J, Westerfield M, Harris NS, Lyden P, Lowry TP, Press GA: Spatial attention deficits in patients with acquired or developmental cerebellar abnormality. J Neurosci 1999, 19:5632-5643.

53. Pierce $\mathrm{K}$, Courchesne E: Evidence for a cerebellar role in reduced exploration and stereotyped behavior in autism. Biol Psychiatry 2001 49:655-664.

54. Andersen BB, Pakkenberg B: Stereological quantitation in cerebella from people with schizophrenia. Brit J Psychiatry 2003, 182:354-361.

55. Andersen BB, Gundersen HJ, Pakkenberg B: Aging of the human cerebellum: a stereological study. J Comp Neurol 2003, 466:356-365.

56. Andersen BB: Reduction of Purkinje cell volume in cerebellum of alcoholics. Brain Res 2004, 1007:10-18.

57. Agashiwala RM, Louis ED, Hof PR, Perl DP: A novel approach to non-biased systemic random sampling: a stereologic estimate of Purkinje cells in the human cerebellum. Brain Res 2008, 1236:73-78.

58. Palmen SJMC, Van Engeland H, Hof SC: Neuropathological findings in autism. Brain 2004, 127:2572-2583.

59. Skefos J, Cummings C, Enzer K, Holiday J, Weed K, Levy E, Yuce T, Kemper T, Bauman M: Regional alterations in Purkinje cell density in patients with autism. PLoS One 2014, 9:e81255.

60. Wegiel J, Kuchna I, Nowicki K, Imaki H, Wegiel J, Ma SY, Azmitia EC, Banerjee P, Flory M, Cohen IL, London E, Brown WT, Komich Hare C, Wisniewski T: Contribution of olivofloccular circuitry developmental defects to atypical gaze in autism. Brain Res 2013, 1512:106-122.

61. Ghatak NR, Santoso RA, McKinney WM: Cerebellar degeneration following long-term phenytoin therapy. Neurology 1976, 26:818-820.

62. Rapport RL, Shaw CM: Phenytoin-related cerebellar degeneration without seizures. Ann Neurol 1977, 2:437-439.

63. McLain LW Jr, Martin JT, Allen JH: Cerebellar degeneration due to chronic phenytoin therapy. Ann Neurol 1980, 7:18-23.

64. Whitney ER, Kemper TL, Bauman ML, Rosene DL, Blatt GJ: Cerebellar Purkinje cells are reduced in a subpopulation of autistic brains: a stereological experiment using calbindin-D28k. Cerebellum 2008, 7:406-416.

65. Yip J, Soghomonian JJ, Nguyen L, Blatt GJ: GAD 67 mRNA decrease in cerebellar Purkinje cells in autism: pathophysiological implications. Acta Neuropathol 2007, 113:559-568.

66. Kreczmanski P, Heinsen H, Mantua V, Woltersdorf F, Masson T, Ulfig N, Schmidt-Kastner R, Korr H, Steinbusch HWM, Hof PR, Schmitz C: Volume, neuron density and total neuron number in five subcortical regions in schizophrenia. Brain 2007, 130:678-692.

67. Bogerts B: Zur Neuropathologie der Schizophrenien. Fortschr Neurol Psychiatr 1984, 52:428-437.

68. Lauer M, Senitz D, Beckmann H: Increased volume of the nucleus accumbens in schizophrenia. J Neural Transm 2001, 108:645-660.

69. Pakkenberg B: Pronounced reduction of total neuron number in mediodorsal thalamic nucleus and nucleus accumbens in schizophrenics. Arch Gen Psychiatry 1990, 47:1023-1028.
70. Sears LL, Vest C, Mohamed S, Bailey J, Ranson BJ, Piven J: An MRI study of the basal ganglia in autism. Progr Neuropsychopharmacol Biol Psychiatry 1999, 23:613-624.

71. Hollander E, Anagnostou E, Chaplin W, Esposito K, Haznedar MM, Licalzi E, Wasserman S, Soorya L, Buchsbaum M: Striatal volume on magnetic resonance imaging and repetitive behaviors in autism. Biol Psychiatry 2005, 58:226-232.

72. Langen M, Durston S, Staal WG, Palmen SJ, van Engeland H: Caudate nucleus is enlarged in high-functioning medication-naive subjects with autism. Biol Psychiatry 2007, 62:262-266.

73. Hardan AY, Kilpatrick M, Keshavan MS, Minshew NJ: Motor performance and anatomic magnetic resonance imaging (MRI) of the basal ganglia in autism. J Child Neurol 2003, 18:317-324.

74. Thompson PM, Giedd JN, Woods RP, MacDonald D, Evans AC, Toga AW: Growth patterns in the developing brain detected by using continuum mechanical tensor maps. Nature 2000, 404:190-193.

75. Sowell ER, Thompson PM, Holmes CJ, Jernigan TL, Toga AW: In vivo evidence for post-adolescent brain maturation in frontal and striatal regions. Nat Neurosci 1999, 2:859-861.

76. Voelbel GT, Bates ME, Buckman JF, Pandina G, Hendren RL: Caudate nucleus volume and cognitive performance: are they related in childhood psychopathology? Biol Psychiatry 2006, 60:942-950.

77. Heimer L, Alheid GF, de Olmos JS, Groenewegen HJ, Haber SN, Harlan RE, Zahm DS: The accumbens: beyond the core-shell dichotomy. J Neuropsychiatry Clin Neurosci 1997, 9:354-381.

78. Day JJ, Carelli RM: The nucleus accumbens and Pavlovian reward learning. Neuroscientist 2007, 13:148-159.

79. Mogenson GJ, Jones DL, Yim CY: From motivation to action: functional interface between the limbic system and the motor system. Progr Neurobiol 1980, 14:69-97.

80. Bailey DB Jr, Hatton DD, Mesibov G, Ament N, Skinner M: Early development, temperament, and functional impairment in autism and fragile X syndrome. J Autism Dev Disord 2000, 30:49-59.

81. Kaufmann WE, Cortell R, Kau AS, Bukelis I, Tierney E, Gray RM, Cox C, Capone GT, Stanard P: Autism spectrum disorder in fragile $\mathrm{X}$ syndrome: communication, social interaction, and specific behaviors. Am J Med Gen Part A 2004, 129A:225-234.

82. Hatton DD, Sideris J, Skinner M, Mankowski J, Bailey DB, Roberts J, Mirrett P: Autistic behavior in children with fragile $X$ syndrome: prevalence, stability, and the impact of FMRP. Am J Med Gen Part A 2006, 140A:1804-1813.

83. Harris SW, HessI D, Goodlin-Jones B, Ferranti J, Bacalman S, Barbato I, Tassone F, Hagerman PJ, Herman H, Hagerman RJ: Autism profiles of males with fragile X syndrome. Am J Ment Retard 2008, 113:427-438.

84. Brown WT, Cohen IL: Fragile $X$ syndrome and autism spectrum disorders. In The Neuroscience of Autism Spectrum Disorders. Edited by Buxbaum JD, Hof PH. Amsterdam: Elsevier, Inc; 2013:409-419.

85. Gothelf D, Furfaro JA, Hoeft F, Eckert MA, Hall SS, O'Hara R, Erba HW, Ringel J, Hayashi KH, Patnaik S, Golianu B, Kraemer HC, Thompson PM, Piven J, Reiss AL: Neuroanatomy of fragile $X$ syndrome is associated with aberrant behavior and the fragile $\mathrm{X}$ mental retardation protein (FMRP). Ann Neurol 2008, 63:40-51.

86. Fatemi SH, Folsom TD: Dysregulation of fragile $\mathrm{X}$ mental retardation protein and metabotropic glutamate receptor 5 in superior frontal cortex of individuals with autism: a postmortem brains study. Mol Autism 2011, 2:6. doi:10.1186/2040-2392-2-6.

87. Kemper TL, Bauman ML: The contribution of neuropathologic studies to the understanding of autism. Neurol Clin 1993, 11:175-187.

88. Schumann CM, Hamstra J, Goodlin-Jones BL, Lotspeich LJ, Kwon H, Buonocore MH, Lammers CR, Reiss AL, Amaral DG: The amygdala is enlarged in children but not adolescents with autism; the hippocampus is enlarged at all ages. J Neurosci 2004, 24:6392-6401.

89. Baron-Cohen S, Ring HA, Bullmore ET, Wheelwright S, Ashwin C, Williams SC: The amygdala theory of autism. Neurosci Biobehav Rev 2000, 24:355-364.

90. Ahlsen G, Rosengren L, Belfrage M, Palm A, Haglid K, Hamberger A, Gillberg C: Glial fibrillary acidic protein in the cerebrospinal fluid of children with autism and other neuropsychiatric disorders. Biol Psychiatry 1993, 33:734-743.

91. Laurence JA, Fatemi SH: Glial fibrillary acidic protein is elevated in superior frontal, parietal and cerebellar cortices of autistic subjects. Cerebellum 2005, 4:206-210. 
92. Vargas DL, Nascimbene C, Krishnan C, Zimmerman AW, Pardo CA: Neuroglial activation and neuroinflammation in the brain of patients with autism. Ann Neurol 2005, 57:67-81.

93. Perea G, Navarrete M, Araque A: Tripartite synapses: astrocytes process and control synaptic information. Trends Neurosci 2009, 32:421-431.

94. Alexander GE, DeLong MR, Strick PL: Parallel organization of functionally segregated circuits linking basal ganglia and cortex. Ann Rev Neurosci 1986, 9:357-381.

95. Muris P, Steerneman P, Merckelbach H, Holdrinet I, Meesters C: Comorbid anxiety symptoms in children with pervasive developmental disorders. J Anxiety Disord 1998, 12:387-393.

96. Stoner R, Chow ML, Boyle MP, Sunkin SM, Mouton PR, Roy S, Wynshaw-Boris A, Colamarino SA, Lein ES, Courchesne E: Patches of disorganization in the neocortex of children with autism. N Engl J Med 2014, 370:1209-1219.

97. Coleman PD, Romano J, Lapham L, Simon W: Cell counts in cerebral cortex of an autistic patient. J Autism Dev Disord 1985, 15:245-255.

98. Bailey A, Luthert P, Dean A, Harding B, Janota I, Montgomery M, Rutter M, Lantos P: A clinicopathological study of autism. Brain 1998, 121:889-905.

99. Duvernoy HM: The human hippocampus. München: JF Bergmann Verlag; 1988:166.

100. Honer WG, Bassett AS, Falkai P, Beach TG, Lapointe JS: A case study of temporal lobe development in familial schizophrenia. Psychol Med 1996, 26:191-195.

101. Falkai P, Schneider-Axmann T, Honer WG: Entorhinal cortex pre-alpha cell clusters in schizophrenia: quantitative evidence of a developmental abnormality. Biol Psychiatry 2000, 47:937-943.

102. DiCiccio-Bloom E, Lord C, Zwaigenbaum L, Courchesne E, Dager SR, Schmitz C, Schultz RT, Crawley J, Young L: The developmental neurobiology of autism spectrum disorder. J Neurosci 2006, 26:6897-6906.

103. Kern JK, Geier DA, Sykes LK, Geier MR: Evidence for neurodegeneration in autism spectrum disorder. Trans/ Neurodegener 2013, 2:17.

104. Hof PR, Knabe R, Bovier P, Bouras C: Neuropathological observations in a case of autism presenting with self-injury behavior. Acta Neuropathol 1991, 82:321-326.

105. Fatemi SH, Aldinger KA, Ashwood P, Bauman ML, Blaha CD, Blatt GJ, Chauhan A, Chauhan V, Dager SR, Dickson PE, Estes AM, Goldovitz D, Heck DH, Kemper TL, King BH, Martin LA, Millen KJ, Mittleman G, Mosconi MW, Persico AM, Sweeney JA, Webb SJ, Welsh JP: Consensus paper: pathological role of the cerebellum in autism. Cerebellum 2013, 11:777-807.

106. Korbo L, West M: No loss of hippocampal neurons in AIDS patients. Acta Neuropathol 2000, 99:529-533.

107. West MJ, Gundersen HJG: Unbiased stereological estimation of the number of neurons in the human hippocampus. J Comp Neurol 1990, 296:1-22.

108. West MJ, Kawas CH, Stewart WF, Rudow GL, Troncoso JC: Hippocampal neurons in pre-clinical Alzheimer's disease. Neurobiol Aging 2004, 25:1205-1212.

109. Pakkenberg B, Møller A, Gundersen HJ, Mouritzen Dam A, Pakkenberg H: The absolute number of nerve cells in substantia nigra in normal subjects and in patients with Parkinson's disease estimated with an unbiased stereological method. J Neurol Neurosurg Psychiatry 1991, 54:30-33.

110. Chauhan A, Gu F, Essa MM, Wegiel J, Kaur K, Brown WT, Chauhan V: Brain region-specific deficit in mitochondrial electron transport chain complex in children with autism. J Neurochem 2011, 117:209-220.

111. Gu F, Chauhan V, Kaur K, Brown WT, LaFauci G, Wegiel J, Chauhan A: Alterations in mitochondrial DNA copy number and the activities of electron transport chain complexes and pyruvate dehydrogenase in the frontal cortex from subjects with autism. Trans/ Psychiatry 2013, 3:e299. doi:10.1038/tp.2013.68

112. Tang G, Rios PG, Kuo S-H, Akman HO, Rosoklija G, Tnji K, Dwork A, Schon EA, DiMauro S, Goldman J, Sulzer D: Mitochondrial abnormalities in temporal lobe of autistic brain. Neurobiol Dis 2013, 54:349-361.

113. Sajdel-Sulkowska EM, Lipinsk B, Windom H, Audhya T, McGinnis W: Oxidative stress in autism: elevated cerebellar 3-nitrotyrosine levels. Am J Bioch Biotechnol 2008, 4:73-84.

114. Chauhan A, Audhya T, Chauhan V: Brain region-specific glutathione redox imbalance in autism. Neurochem Res 2012, 37:1681-1689.
115. Wegiel J, Frackowiak J, Mazur-Kolecka B, Schanen NC, Cook EH Jr, Sigman M, Brown WT, Kuchna I, Wegiel J, Nowicki K, Imaki H, Ma SY, Chauhan A, Chauhan V, Miller DL, Mehta PD, Flory M, Cohen IL, London E, Reisberg B, de Leon MJ, Wisniewski T: Abnormal intracellular accumulation and extracellular $A \beta$ deposition in idiopathic and Dup15q11.2-q13 autism spectrum disorders. PLoS One 2012, 7(5):e35414. doi:10,1731/journal. pone.0035414

116. Frackowiak J, Mazur-Kolecka B, Schanen NC, Brown WT, Wegiel J: The link between intraneuronal $\mathrm{N}$-truncated amyloid b-peptide and oxidatively modified lipids in idiopathic autism and dup(15q11.2-q13)/autism. Acta Neuropathol Comm 2013, 1:61.

\section{doi:10.1186/s40478-014-0141-7}

Cite this article as: Wegiel et al:: Stereological study of the neuronal number and volume of 38 brain subdivisions of subjects diagnosed with autism reveals significant alterations restricted to the striatum, amygdala and cerebellum. Acta Neuropathologica Communications 2014 2:141.

\section{Submit your next manuscript to BioMed Central and take full advantage of:}

- Convenient online submission

- Thorough peer review

- No space constraints or color figure charges

- Immediate publication on acceptance

- Inclusion in PubMed, CAS, Scopus and Google Scholar

- Research which is freely available for redistribution

Submit your manuscript at www.biomedcentral.com/submit
C) Biomed Central 